\title{
Archaic chaos: intrinsically disordered proteins in Archaea
}

\author{
Bin Xue ${ }^{1,2}$, Robert W Williams ${ }^{3}$, Christopher J Oldfield ${ }^{2,4}$, A Keith Dunker ${ }^{1,2}$, Vladimir N Uversky ${ }^{1,2,5^{*}}$ \\ From The ISIBM International Joint Conferences on Bioinformatics, Systems Biology and Intelligent \\ Computing (IJCBS) \\ Shanghai, China. 3-8 August 2009
}

\begin{abstract}
Background: Many proteins or their regions known as intrinsically disordered proteins (IDPs) and intrinsically disordered regions (IDRs) lack unique 3D structure in their native states under physiological conditions yet fulfill key biological functions. Earlier bioinformatics studies showed that IDPs and IDRs are highly abundant in different proteomes and carry out mostly regulatory functions related to molecular recognition and signal transduction. Archaea belong to an intriguing domain of life whose members, being microbes, are characterized by a unique mosaic-like combination of bacterial and eukaryotic properties and include inhabitants of some of the most extreme environments on the planet. With the expansion of the archaea genome data (more than fifty archaea species from five different phyla are known now), and with recent improvements in the accuracy of intrinsic disorder prediction, it is time to re-examine the abundance of IDPs and IDRs in the archaea domain.
\end{abstract}

Results: The abundance of IDPs and IDRs in 53 archaea species is analyzed. The amino acid composition profiles of these species are generally quite different from each other. The disordered content is highly species-dependent. Thermoproteales proteomes have 14\% of disordered residues, while in Halobacteria, this value increases to $34 \%$. In proteomes of these two phyla, proteins containing long disordered regions account for $12 \%$ and $46 \%$, whereas $4 \%$ and $26 \%$ their proteins are wholly disordered. These three measures of disorder content are linearly correlated with each other at the genome level. There is a weak correlation between the environmental factors (such as salinity, $\mathrm{pH}$ and temperature of the habitats) and the abundance of intrinsic disorder in Archaea, with various environmental factors possessing different disorder-promoting strengths. Harsh environmental conditions, especially those combining several hostile factors, clearly favor increased disorder content. Intrinsic disorder is highly abundant in functional Pfam domains of the archaea origin. The analysis based on the disordered content and phylogenetic tree indicated diverse evolution of intrinsic disorder among various classes and species of Archaea.

Conclusions: Archaea proteins are rich in intrinsic disorder. Some of these IDPs and IDRs likely evolve to help archaea to accommodate to their hostile habitats. Other archaean IDPs and IDRs possess crucial biological functions similar to those of the bacterial and eukaryotic IDPs/IDRs.

\section{Introduction}

\section{Introducing Archaea}

It is known that all the living systems on the Earth can be divided into three large domains, the Bacteria, the Archaea, and the Eucarya, each containing at least two kingdoms [1-3]. The Bacteria and the Archaea domains

\footnotetext{
* Correspondence: vuversky@iupui.edu

${ }^{1}$ Center for Computational Biology and Bioinformatics, Indiana University School of Medicine, Indianapolis, IN 46202, USA
}

include single-celled microorganisms, prokaryotes. Although archaea are similar to bacteria phenotypically (both have no cell nucleus or any other cellular organelles inside their cells and are very often similar in size and shape), and despite a bacterial organization of archeae chromosome (messenger RNA with Shine-Dalgarno sequences, genes assembled in operons, a single origin of bidirectional replication), these two domains of life are clearly different at the molecular level, and some 
of the archaea genes, metabolic pathways and proteins (especially ribosomal proteins and proteins involved in transcriptions and translation) are more closely related to those of eukaryotes [4-11]. For example, all eubacteria exhibit very similar subunit pattern in their RNA polymerases (in terms of numbers and sizes), whereas this pattern is not related to that seen in the archaea or the eukaryotes [4], and several archaea and eukaryotic ribosomal protein homologues have no apparent counterpart among the bacteria $[5,6]$. On the other hand, archaea and eukaryotes are sufficiently dissimilar and diverged early, and, therefore, they could not be placed in a single domain of life either [1]. Generally speaking, according to the detailed molecular analysis and comparative genomics, archaea are characterized by a combination of unique properties, such as left-handed isoprenoids containing glycerolipids, and mosaic bacterial and eukaryotic features [12].

Based on sequences of ribosomal RNAs, archaea were first classified as a separate group of prokaryotes in 1977 [13]. Before that time prokaryotes were considered as a single group. The term "archaea" was introduced in 1987 to denote apparent primitive nature of corresponding organisms especially in comparison with the eukaryotes [2]. It is estimated that the total number of phyla in the archaea domain range from 18 to 23, of which only 8 phyla have representatives that have been grown in culture and studied directly [14]. In fact, most of the culturable and well-investigated species of archaea belong to the two main phyla, Crenarchaeota, and Euryarchaeota. Three new phyla, Thaumarchaeota, Nanoarchaeota, and Korarchaeota, were discovered very recently. Nanoarchaeota contains a nanosized symbiotic hyperthermophilic archaeon Nanoarchaeum equitans from a submarine hot vent, which grows attached to the surface of a specific archaeal host, a new member of the genus Ignicoccus[15]. Based on the small subunit rRNA phylogeny it has been concluded that Korarchaeota comprises a group of microorganisms that may have diverged early from the major archaeal phyla Crenarchaeota and Euryarchaeota, share many features of both of these main phyla, but are most closely related to the Crenarchaeota[16]. Members of the Thaumarchaeota phylum are mesophilic archaea which are different from hyperthermophilic Crenarchaeota to which they were originally ascribed [17].

It is recognized now that archaea are an important component of the biosphere [11], play important roles in the carbon and nitrogen cycle, and may contribute up to $20 \%$ of the total biomass on Earth [18]. The unique feature of some archaea is their ability to produce methane gas in anaerobic environments; i.e., methanogenesis. Another uniqueness of the archaea is their ability to utilize a great variety of energy sources ranging from sugars, to using ammonia, sulfur, metal ions and even hydrogen gas as nutrients; some salt-tolerant archaea (the Halobacteria) use sunlight as a source of energy; other archaea use $\mathrm{CO}_{2}$ in the atmosphere as a source of carbon via the carbon-fixation process, which is powered by inorganic sources of energy, rather than by capturing sunlight [19-21]. Many archaea are able to grow at temperatures above $100^{\circ} \mathrm{C}$ and are found in geysers, black smokers, and oil wells. The archaeon Methanopyrus kandleri (Strain 116) can effectively grow at $122^{\circ} \mathrm{C}$ and high hydrostatic pressure $(20 \mathrm{MPa})$, which is the highest recorded temperature at which an organism will grow [22]. Others are found in very cold habitats and still others can survive in highly saline, acidic (at pHs as low as 0 , which is equivalent to $1.2 \mathrm{M}$ sulfuric acid), or alkaline water [23]. In addition to these extremophiles (halophiles, hyperthermophiles, thermophiles, psychrophiles, alkaliphiles, and acidophiles), many archaea are mesophiles that grow in much milder conditions, such as marshland, sewage, the oceans, and soils [24]. Although for a long time Archaea, in particular Crenarchaeota, were considered ecologically insignificant, presuming to occupy mainly extreme and unusual environments, it is becoming increasingly evident that previously unrecognized members of the Archaea are abundant, globally distributed, and welladapted to more pedestrian lifestyles and niches, including symbiotic partnership with eukaryotic hosts [25]. Archaea are particularly numerous in the oceans, and the archaea in plankton (as part of the picoplankton) may be one of the most abundant groups of organisms on the planet, accounting for up to $40 \%$ of the bacterioplankton in deep ocean waters [26]. Therefore, it has been pointed out that the study of archaea is essential to understand the history of molecular mechanisms and metabolism diversity and to unravel the mechanisms by which life can sustain in extreme environments [12].

\section{Introducing intrinsically disordered proteins}

As verified by an increasing number of experimental observations, more and more proteins or their regions have been found to lack unique 3D structure in their native states under physiological conditions. These regions and proteins, known as Intrinsically Disordered

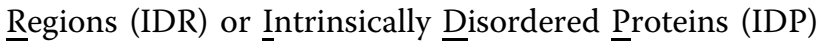
among different other names [27-30], present in solution as conformational ensembles containing large number of widely different conformations that are in rapid interconversion on different time scales. The protein intrinsic disorder phenomenon is rapidly becoming wellaccepted in modern protein science. Unlike structured proteins, IDPs stay as an ensemble of flexible conformations [27,31-33]. Although without stable 3D structures 
and in contradiction to the traditional sequence-structure-function paradigm, IDPs play a number of crucial functional roles in living organisms, especially in vital biological processes, such as signaling, recognition, and regulation $[27,31,32]$. According to a statistical study on SwissProt database, 238 out of 710 SwissProt functional keywords are strongly positively correlated with intrinsic disorder, while another 302 functional keywords mostly characterizing various catalytic activities are strongly negatively correlated with IDR [34].

Due to their crucial functional roles, IDPs are highly abundant in all species. According to computational predictions by PONDR ${ }^{\circ}$-VLXT, typically $7-30 \%$ prokaryotic proteins contain long disordered regions of more than 30 consecutive residues, whereas in eukaryotes the amount of such proteins reaches $45-50 \%$ [28,35-38]. Another estimation based on DISOPRED2 achieved similar results: around $2.0 \%, 4.2 \%$, and $33.0 \%$ of proteins in archaea, bacteria, and eukaryota have long disordered segments with 30 or more residues [39]. Higher contents of long IDR were reported in a study using another computational tool, DisEMBL [40]. In that study, $23 \sim 56 \%, 15 \sim 40 \%$, and $25 \sim 78 \%$ of proteins in archaea, bacteria, and eukaryota were predicted to have IDR longer than 40 residues. In spite of the disagreement between the reported values, the general trend among the three domains of life is quite consistent: at the proteome level, eukaryotes have much more disordered proteins than bacteria and archaea. This is a reflection of the vital roles of IDPs and IDRs in signaling and regulation. Furthermore, not only at proteome level, but even in PDB, which is biased to structured proteins, intrinsic disorder is also very abundant, and almost $70 \%$ of proteins in PDB have IDRs which are indicated by missing electron density [41].

Despite of the solid proofs of the relative abundance of IDPs in nature, their origin is still a mystery. Where are they coming from? How do they evolve? Although all of the three domains of life have a considerable amount of intrinsic disorder, modern species have evolved so effectively that ancient information is no longer easy to retrieve. In this meaning, archaea could be an excellent candidate to tell the story of what happened thousands of millions years ago. Since archaea are prokaryotes (they have no cell nucleus or any other organelles within the cell), they seem to have appeared early in the evolution. Furthermore, many archaea live and grow at extreme conditions, such as high temperature, which are believed to be very similar to the conditions at the early time of planet formation. Finally, archaea have genes and several metabolic pathways which are more similar to eukaryotes than bacteria. Hence, by taking into account the facts that eukaryotes need more signaling and regulation due to their biological complexity, and that eukaryotes are highly enriched in IDRs and IDPs, archaea may provide interesting information about the evolution of intrinsic disorder.

Previous studies discussed above provided very enlightening information on the abundance of intrinsic disorder in archaea. However, at that time the number of species available for the bioinformatics analysis was rather limited. Studies utilizing PONDR ${ }^{\circ}$-VLXT, DISOPRED2, and DisEMBL had only 7, 6, and 20 archaea species, respectively $[39,40,42]$. This limited number of species restricted the study on the phylogenetic relations among the archaea species. Hence, with the expansion of archaea genome data (more than fifty archaea species from five different phyla are known now), it is necessary to re-examine the previous results and to explore new information. Here, we systematically studied the abundance of intrinsic disorder in archaea and explored the functional and evolutionary roles of intrinsic disorder in this domain of life.

\section{Methods}

\section{Datasets}

All protein sequences from the completed 53 archaea genome were downloaded from the ExPASy proteomics server as of Jan. 2009 [43]. The taxonomy of these archaea is listed in Table S1 (see additional file 1). Note: In the following discussion, names of phyla are in bold; names of classes and orders are in bold italic; whereas names of species are in italic. All five known phyla of archaea are included in this study: Crenarchaeota and Euryarchaeota have 15 and 32 species, respectively, each of the Thaumarchaeota and Nanoarchaeota phyla has two species; and finally there is only one species in the Korarchaeota phyla. All the species in Korarchaeota, Thaumarchaeota, and Nanoarchaeota can be grouped into one class corresponding to that phylum. Although Crenarchaeota has 15 species, all of these species also belong to a single class, Thermoprotei. Hence, these species could be combined together and be analyzed as a single one. Euryarchaeota is the most complicated phylum of archaea. It has 7 classes with one to twelve species in each of them. In order to take this complexity into consideration, following analysis will be conducted at three different levels: 5 phyla, 11 classes, and 53 species.

\section{Disorder predictions}

In this study, two types of intrinsic disorder predictors were utilized, per-residue predictors and binary classifiers. Per-residue predictors provide the distribution of the propensity for intrinsic disorder over the amino acid sequence, whereas binary classifiers identify entire protein as wholly ordered or wholly disordered. The 
per-residue predictors were used to generate two means for the evaluation of abundance of intrinsic disorder in a given protein, the total amount of disordered residues and the number of long disordered regions containing $>30$ consecutive amino acid residues predicted to be disordered. The binary classifiers were used to evaluate the number of wholly disordered proteins in a given proteome.

\section{Per-residue disorder predictions}

In this study, per-residue disorder predictors PONDR ${ }^{\circ}$ VLXT [36] and PONDR ${ }^{\circ}$-VSL2 [44] were utilized.
PONDR $^{\circ}$-VLXT is the first disorder predictor which was designed by using neural networks. It is very sensitive to the changes of local compositional profile. One of its prominent properties is the frequently occurring dips on the plot of disorder score (see Figure 1). These dips correspond to hydrophobic segments with the increased propensity to order that are flanked by disordered regions. many of these segments are found to be very important in molecular recognition, signaling and regulation. They are now recognized as a Molecular Recognition Feature (MoRF) $[38,45] . \mathrm{PONDR}^{\circ}-\mathrm{VS} L 2$ is
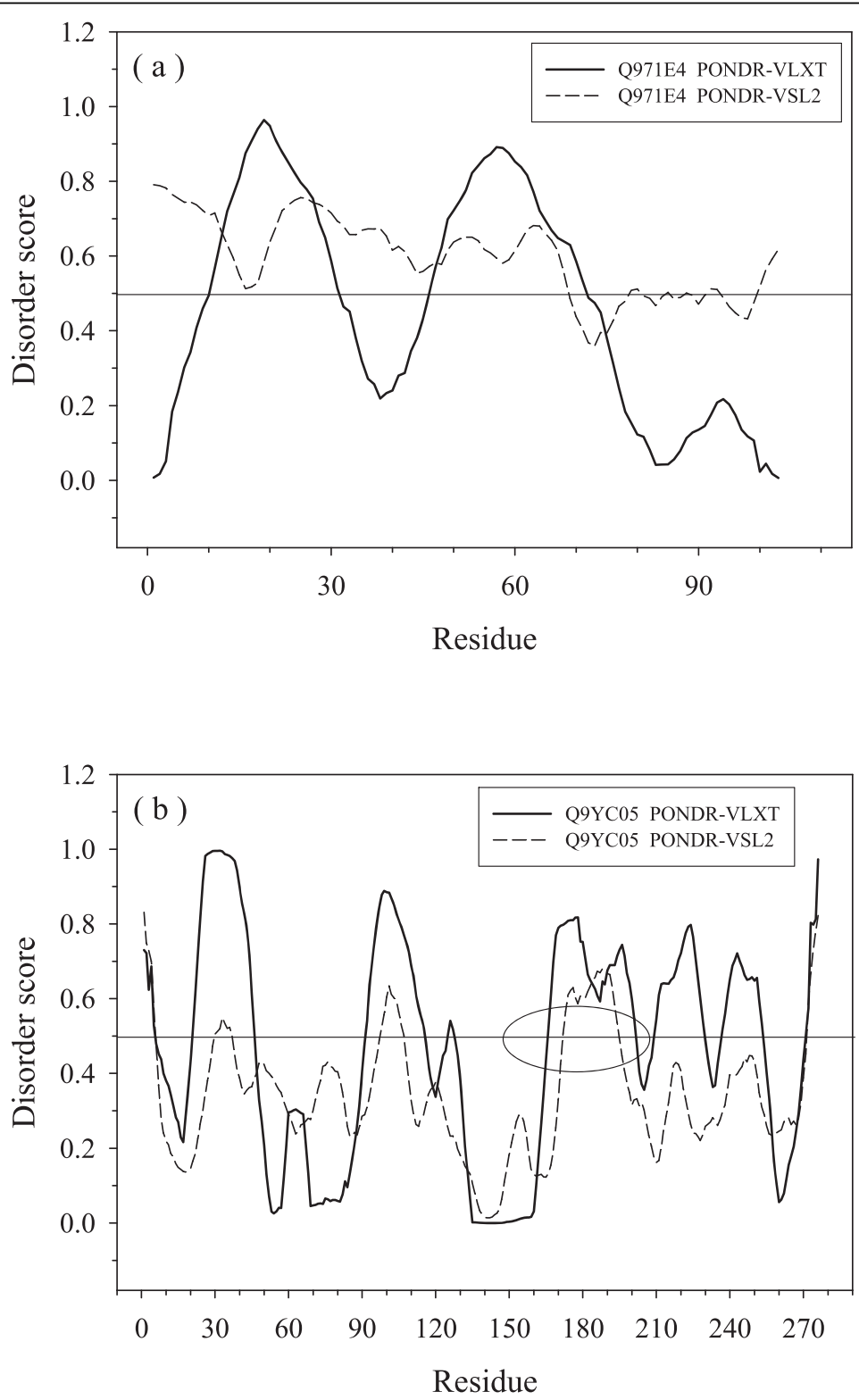

Figure 1 Comparison of disorder prediction between PONDR-VLXT and PONDR-VSL2 for (a) Q971E4 and (b) Q9YC05: The solid line is the disorder score of PONDR-VLXT, while the dashed line is from PONDR-VSL2. The line at (a) shows a dip in VLXT prediction while VSL2 predicts the long segment to be disordered. The circle in (b) represents a long disordered region predicted by VLXT, but missed by VSL2. 
composed of a set of support vector machines and was trained on datasets containing disordered regions of various lengths. It is one of the most accurate predictors developed so far. Both PONDR ${ }^{\circ}$-VLXT and VSL2 have been applied in genome-wide studies on protein intrinsic disorder. The results of these analyses clearly indicated the existence of noticeable differences between these two predictors. However, the sources of these differences and their underlying biological significance have not been clearly uncovered as of yet. Figure 1 represents the illustrative example of the disorder evaluation by $\mathrm{PONDR}^{\circ}$-VLXT and PONDR ${ }^{\circ}$-VSL2 predictors in two unrelated proteins. This figure illustrates the typical feature of the PONDR ${ }^{\circ}$-VLXT plot which contains many sharp dips. As a result, long disordered regions are divided into a series of short disordered regions by these dips. Consequently, PONDR ${ }^{\circ}-\mathrm{VLXT}^{-}$ may under-estimate the ratio of long disordered regions as shown in Figure 1(a). On the other hand, although PONDR $^{\circ}$-VSL2 is more accurate than PONDR ${ }^{\circ}$-VLXT on short disordered/structured regions, it was also trained using a set of short protein segments. As a result, for proteins that tend to have intersected disordered/structured segments, PONDR ${ }^{\circ}$-VSL2 may also have lower ratio for long disordered regions as indicated by Figure 1(b). Hence, it would be beneficial to combine the results of several different predictors. However, in this study, due to reasons discussed above, we will focus on the results from the PONDR ${ }^{\circ}$-VSL2.

\section{Binary disorder classification}

Based on the per-residue disorder prediction, a Cumulative Distribution Function (CDF) can be obtained to describe the disorder status of the entire protein $[37,42,46]$. Basically, CDF is based on a cumulated histogram of disordered residues at various disorder scores. By definition, structured proteins will have more structured residues and less disordered residues. Therefore, the CDF curve of a structured protein will increase very quickly on the side of low disorder score, and then go flat on the side of high disorder score. On the other hand, for disordered proteins, the CDF curve will move upward slightly in regions of low disorder score, then rapidly increase in the regions with high disorder scores. Hence, on the 2D CDF plot, structured proteins tend to be located in the upper left half, whereas disordered proteins are predominantly located at the lower right half of the plot. By comparing the locations of CDF curves for a group of fully disordered and fully structured proteins, a boundary line between these two groups of proteins can be identified. Then, this boundary can be used to classify any given protein as wholly ordered or wholly disordered. Proteins whose CDF curves are above the boundary line are mostly structured, whereas proteins with CDF curves located below the boundary are mostly disordered $[37,42,46]$. The distance of a curve from the CDF boundary can also be used as a kind of measure of the disordered (structured) status of a protein. This distance is further referred as CDF-distance. Originally, CDF analysis was developed based on the results of the PONDR ${ }^{\circ}$-VLXT [28]. Recently, other five CDF predictors were built using the outputs of the PONDR ${ }^{\circ}$-VSL2 [44], PONDR ${ }^{\circ}$-VL3 [47], IUPred [48], FoldIndex [49], and TopIDP [50]. Among these various CDFs, $\mathrm{PONDR}^{\circ}$-VSL2-CDF achieved the highest accuracy, $5-10 \%$ higher than the accuracy of the second best predictor [46].

Another method of measuring the disordered status of the entire protein is a Charge-Hydropathy $(\mathrm{CH})$ plot [29]. CH-plot takes the averaged Kyte-Doolittle hydrophobicity [51] and an absolute mean net charge of a protein chain as the coordinates of the $\mathrm{X}$ - and $\mathrm{Y}$-axis, respectively. This plot represents each protein as a single point in such a 2D graph. Since extended disordered proteins typically contain fewer hydrophobic residues and more charged residues than ordered proteins, these two types occupy different areas in the $\mathrm{CH}$-phase diagram and can even be separated by a linear boundary [29]. According to this analysis, all of the proteins located above this boundary line are highly likely to be disordered, whereas proteins below this line are structured. On the $\mathrm{CH}$-plot, the vertical distance from the location of a protein to the boundary line is then taken as a scale of disorder (or structure) tendency of a protein. This distance is further referred as $\mathrm{CH}$-distance.

$\mathrm{CDF}$ - and $\mathrm{CH}$-plots have different underlying principles. The CDF-plot, being based on the disorder predictors of the $\mathrm{PONDR}^{\circ}$ family, is strongly related to the method of machine learning. Essentially, it is a statistical analysis based on known structures in PDB. The $\mathrm{CH}$ measurement has a very intuitive physicochemical background. Charged residues intend to interact with solvent molecules, while hydrophobic residues prefer to avoid contacts with solvent, therefore aggregating together. Hence, the $\mathrm{CH}$-distance provides very important information about the general compactness and conformation of a polypeptide chain. By combining CDF- and $\mathrm{CH}$-distances in one graph, we have another method called the CH-CDF-plot $[37,52]$. On this plot, each point corresponds to a single protein and represents its $\mathrm{CDF}$-distance at the $\mathrm{X}$-axis and the $\mathrm{CH}$-distance at the Y-axis. $\mathrm{CH}>0$ and $\mathrm{CH}<0$ denote proteins predicted to be disordered and ordered by the $\mathrm{CH}$-plot, respectively. On the other hand, values of $\mathrm{CDF}>0$ represent structured proteins, and $\mathrm{CDF}<0$ correspond to disordered proteins. Hence, the entire field can be divided into four quadrants by cutting lines $\mathrm{CH}=0$ and $\mathrm{CDF}=0$. Lower right quadrant corresponds to proteins predicted to be structured by both $\mathrm{CH}$ and $\mathrm{CDF}$, whereas upper left 
quadrant contains proteins predicted to be is disordered by both methods.

\section{Composition profiling}

To gain insight into the relationships between sequence and disorder, the amino acid compositions of Archaea proteomes were compared using an approach developed for the analysis of intrinsically disordered proteins $[28,53]$. To this end, the fractional difference in composition between a given protein set (an Archaean proteome), and proteins from the Fully Disordered Dataset (FDD) $[46,54]$ was calculated for each amino acid residues as described in $[28,53]$. The fractional difference was calculated as $\left(\mathrm{C}_{\mathrm{X}}-\mathrm{C}_{\mathrm{FDD}}\right) / \mathrm{C}_{\mathrm{FDD}}$, where $\mathrm{C}_{\mathrm{X}}$ is the content of a given amino acid in a given proteome, and $\mathrm{C}_{\mathrm{FDD}}$ is the corresponding content in FDD proteins. These fractional differences for each proteome are then plotted for each amino acid. This analysis was performed using a Composition Profiler, a computational tool that automates this task and graphically summarizes the results [53]. Composition Profiler is available at http://profiler.cs.ucr.edu.

\section{Results and discussion}

\section{Major characteristics of the Archaea proteomes}

Archaea are very abundant in nature, play a number of important roles in the cycle of carbon and nitrogen on earth [18]. Although most of archaea live in ocean, many of these microbes are extremophiles since they live, grow and prosper in extremely harsh environments, such environments of highly salty lakes or hot/ boiling springs. For the cells of "normal" organisms (e.g., mammals), these types of environment are absolutely lethal, since high temperatures or high salt concentrations will inevitably denature proteins of these organisms, invalidate their functions, and terminate crucial biological pathways, eventually leading to the cell death. However, compared to these normal cells, archaea developed special mechanisms to counteract the harmful influence of these environments. The major components involved in these protective mechanisms should directly target the most abundant bio-substance: proteins. Therefore, the comparative analysis of proteomes of various species living at various habitats should provide crucial information on the similarities and differences of these organisms and on the mechanisms of the adaptation.

Figure 2 presents the size distribution of proteomes of various archaea species analyzed in this study. Although 15 species in the first phylum, Crenarchaeota, belong to the same class, they can be divided into three orders: the first order is Desulfurococcales with 4 species; the second order is Sulfolobales having another 4 species; and the last order is Thermoproteales which contains 7

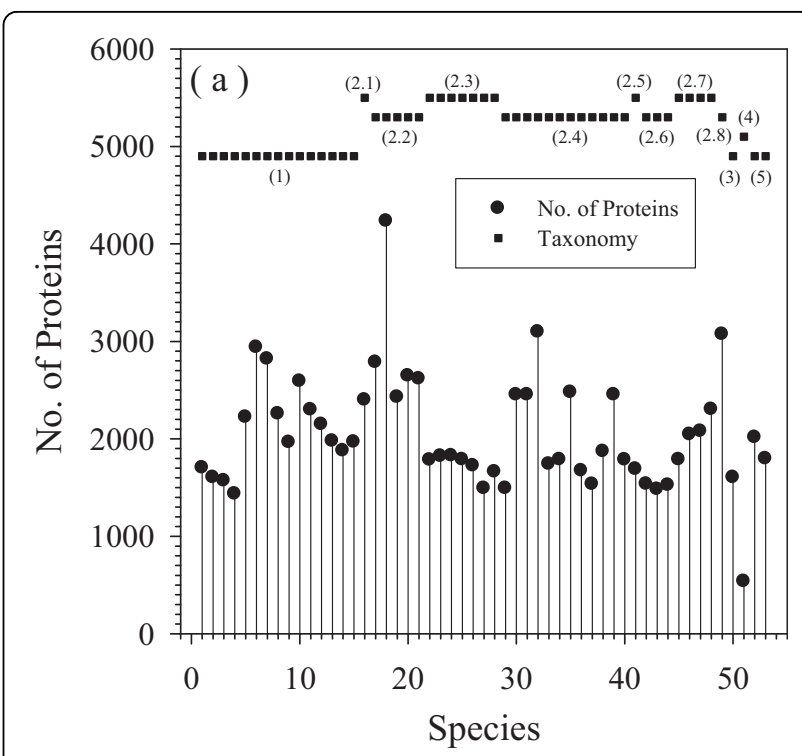

Figure 2 Size of proteome of each species: The $X$-axis is the index of the number of each species, while the $Y$-axis is the number of proteins. Filled circles represent the size of the proteome of each species. Filled squares indicate the taxonomy of archaea with similar species together and on same level. (1), (3)-(5) indicate species in four phyla: Crenarchaeota, Korarchaeota,

Nanoarcgaeota, and Thaumarchaeota. (2.1) - (2.8) are eight different classes in the phylum of Euryarchaeota as shown in Table. 1.

species. After this division is taken into account, the trends in the proteome sizes of these 15 species became obvious. Figure 2 shows that the members of the Desulfurococcales order are relatively uniform and have the smallest proteomes size in this phylum. Two other orders (Sulfolobales and Thermoproteales) still possess large variability in their proteome sizes. In Euryarchaeota, as shown by taxonomy (2.1) - (2.7) and corresponding proteome size in Figure 2, Halobacteria has the largest proteomes; Methanococci and Thermococci have fewer proteins in their proteomes; whereas Methanomicrobia have the largest fluctuations in proteome size among various species. Apparently, all the species with small proteomes are characterized by a globule-like morphology. The relatively large number of proteins in Halobacteria is also expected, since extra proteins may be needed to help these species deal with the high concentrations of ions in their environment. Finally, Uncultured methanogenic archaeon which belong to the Euryarchaeota phylum has more than 3000 proteins and ranks as one of the largest proteomes in Archaea. Korarchaeota and Thaumarchaeota have middle-sized proteomes. Nanoarchaeota have the only representative Nanoarchaeum equitans, which is the simplest species in Archaea being characterized by the smallest proteome and having only 536 proteins. 

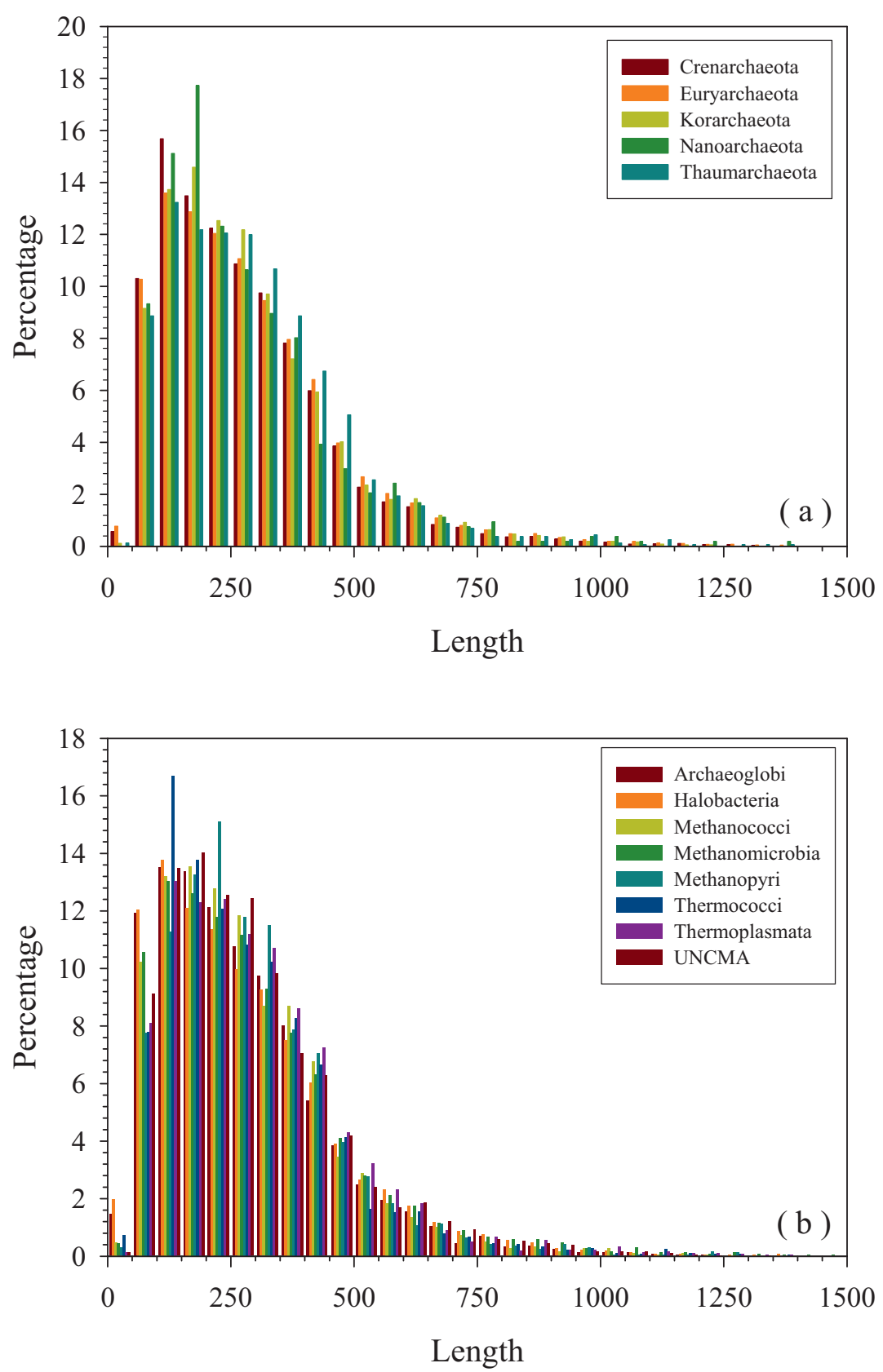

Figure 3 Length distribution of proteins in five phyla (a) and eight classes (b) of Euryarchaeota. X-axis: " $X$ " length of protein; Y-axis: percentage of proteins with " $X$ " length. The upper limit of the $X$-axis is taken as 1500 residues for visualization purposes. However, there are still scattered distributions of proteins beyond this uplimit.

Not only the size of proteome is important, but also the size of proteins in each genome. The length distributions for 5 phyla and 7 classes of Euryarchaeota phylum are shown in Figure 3(a) and Figure 3(b), respectively. Clearly, in general, distributions of protein length among all the species are very similar, although some important subtle differences can be found. The general shape of the distribution is similar to the power- law distribution. All of the species have less than $2 \%$ extremely short proteins (less than 50aa). The most optimal protein length for all species is around $100-$ 200 residues. Proteins with these lengths constitute approximately $25 \%$ of any given proteome. Larger proteins are also very common in all the species: the content of proteins longer than $500 \mathrm{aa}$ is around $10 \%$ or even higher. Very long proteins (longer than 1000 aa) 
are not very common and account for several percent, comparable to the proportion of the extremely short proteins. As shown in Figure 3(a), Thaumarchaeota and Korarchaeota have fewer extremely short and short proteins. However, the members of the Korarchaeota phylum have more middle-sized proteins $(150$ - 250aa), whereas Thaumarchaeota have more proteins with 250 - 500 residues. In addition, Nanoarchaeota has around $5 \%$ percent more middle-sized proteins with 50 - 100 residues. In Figure 3(b), Archaeoglobi and Halobacteria have around 4 times more extremely short proteins than the other 5 classes. The other 5 classes are enriched in longer proteins with $250-450$ residues. In Methanococci, the content of proteins with $50-450$ residues is always the highest.

\section{Amino acid compositions of the Archaea proteomes}

At the next stage, the amino acid compositions of proteins from various Archaea were analyzed. The results of this analysis are shown in Figure 4 as the relative composition profiles calculated for various species as described by Vacic and colleagues [53]. Here, the fractional difference in composition between a given protein set and a set of completely disordered proteins was calculated for each amino acid residue. The fractional difference was evaluated as $\left(C_{\mathrm{X}}-C_{\mathrm{FDD}}\right) / \mathrm{C}_{\mathrm{FDD}}$, where $\mathrm{C}_{\mathrm{X}}$ is
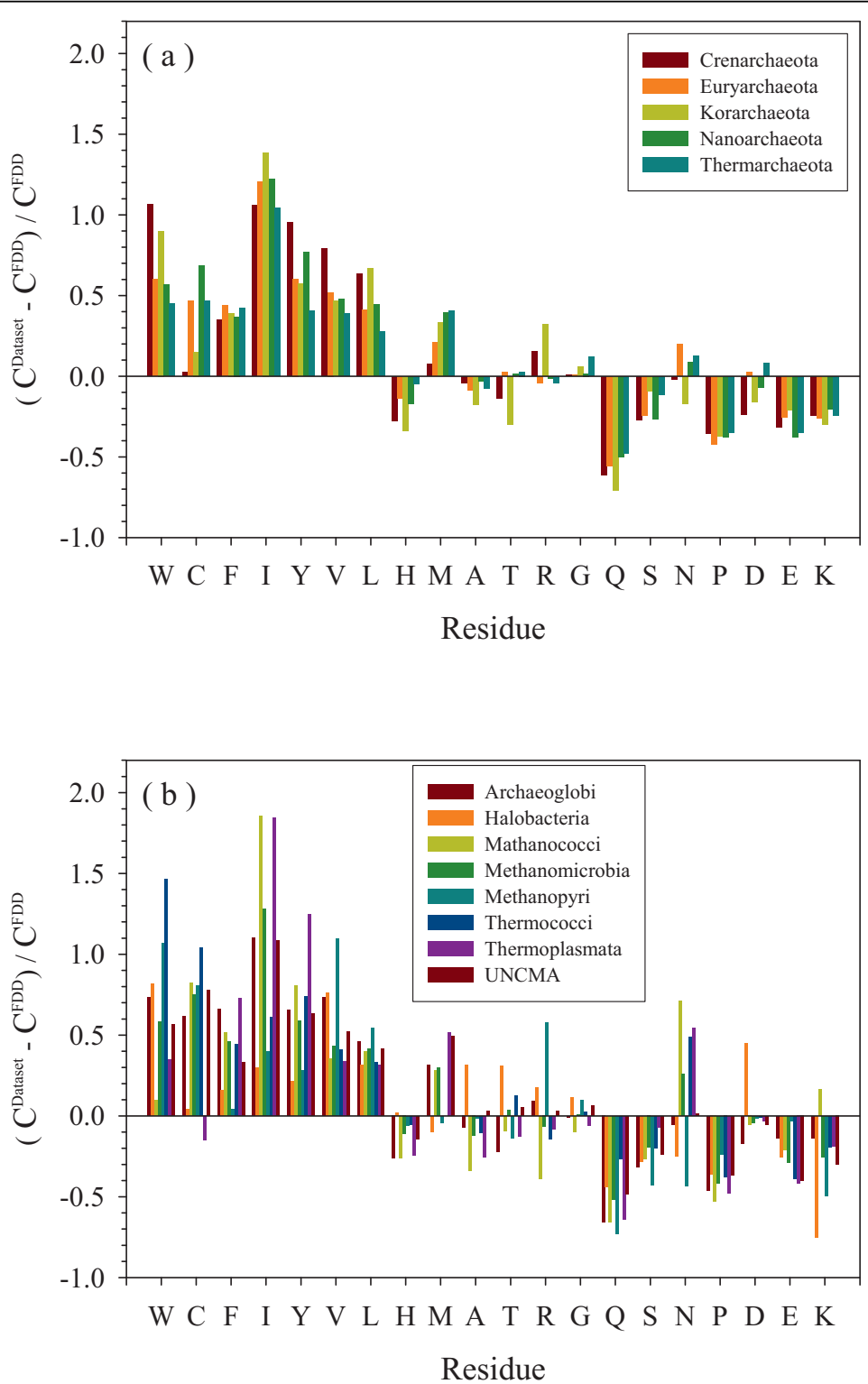

Figure 4 Composition profile of amino acids for (a) five phyla, and (b) eight classes in Euryarchaeota: Residues on the $X$-axis are arranged according to the increasing disorder tendency. Y-axis: the relative compositional profile compared to a fully disordered dataset. 
the content of a given amino acid in a given protein set, and $\mathrm{C}_{\mathrm{FDD}}$ is the corresponding content in the Fully Disordered Dataset (FDD) $[46,54]$. The usefulness of this analysis is determined by the fact that the propensity of a given protein to be intrinsically disordered is determined by a set of specific features of its amino acid sequence and composition $[28,29,50,53,55]$. For example, intrinsically disordered proteins are significantly depleted in bulky hydrophobic (I, L, and V) and aromatic amino acid residues (W, Y, and F), which would normally form the hydrophobic core of a folded globular protein, and also possess a low content of $\mathrm{C}$ and $\mathrm{N}$ residues. These depleted residues, I, L, V, W, F, Y, C and $\mathrm{N}$, were proposed to be called order-promoting amino acids. On the other hand, intrinsically disordered proteins and regions were shown to be substantially enriched in disorder-promoting amino acids: $\mathrm{E}, \mathrm{K}, \mathrm{R}, \mathrm{G}$, Q, S, P and A.

Application of this tool to the analysis of the Archaea proteomes revealed a number of interesting features. Figure 4(a) clearly shows that all 5 phyla contain many more structure-promoting residues (W, C, F, I, Y, V, L) and fewer disorder-promoting residues (Q, S, P, E, K) than the FDD proteins. In Figure 4(a), the content of F, $\mathrm{I}, \mathrm{Q}, \mathrm{P}, \mathrm{E}$, and $\mathrm{K}$ are rather consistent between the 5 phyla, where compared to FDD isoleucine had the highest abundance in all 5 phyla. By comparing each phylum, Crenarchaeota and Korarchaeota have more similarity with each other. They both have a low content of cystein, but are rich in tryptophan. In comparison with other phyla, they are also very similar in their content of H, T, R, and D. Figure 4(b) shows that the contents of $\mathrm{L}, \mathrm{Q}, \mathrm{S}$, and $\mathrm{P}$ are stable among various classes of Euryarchaeota. Halobacteria are very special due to their low content of structure-promoting residues $(C, F$, I, and Y), abnormally large increments in A, T, R, G, and $\mathrm{D}$, and a dramatic decrease in $\mathrm{K}$ abundance. Methanococci show a large increase in (I, N, and K) and a noticeable decrease in (H, A, and R). Methanopyri show a very large increase in $\mathrm{V}$, and $\mathrm{R}$, and a decrease in S, N, and K. Thermoplasmata have much more I, Y, and $M$ than other classes.

Table 1 presents the averaged Kullback-Leibler $[54,56,57]$ divergence among all the phyla and classes. As stated in our previous study, values below 0.01 correspond to high similarities between two datasets; values between 0.01 and 0.05 indicate a gray zone; values larger than 0.05 correspond to the datasets which are unlikely to be similar; and values greater than 0.1 correspond to the non-similar datasets [54]. This Table provides a very straightforward description of the similarity among the various Archaea species and shows that several species are similar to each other in terms of their amino acid compositions.

\section{Disorder distribution in the Archaea proteomes}

The differences in the protein length distributions among the proteomes of various Archaea and in their amino acid compositions lead to another important question: Is intrinsic disorder distributed evenly in all these species or not? The comparison of various disorder contents among 53 species is shown in Figure 5, where the amount of disorder in different Archea proteomes is annotated as the percentage of predicted disordered residues (Figure 5(a)), the amount of long disordered regions (Figure 5(b)), and the amount of wholly disordered proteins (Figure $5(\mathrm{c})$ ). Figure 5 clearly shows that Crenarchaeota have a relatively lower content of disorder than the other four phyla. On the other hand, Korarchaeota have the highest disorder content. In Euryarchaeota, the ratios diverged: Halobacteria have much higher disorder content than other species and Thermococci have the lowest disorder content. These observations indicated the influence of environment on the abundance of intrinsic disorder in a given organism. Halobacteria need to be more adaptive in

Table 1 Kullback-Leibler (KL) distances among 12 classes of 5 archaea phyla

\begin{tabular}{|c|c|c|c|c|c|c|c|c|c|c|c|c|}
\hline & (1) & (2.1) & $(2.2)$ & (2.3) & (2.4) & (2.5) & (2.6) & (2.7) & (2.8) & (3) & (4) & (5) \\
\hline (1) & 1 & 0.012 & 0.091 & 0.065 & 0.019 & 0.049 & 0.012 & 0.041 & 0.016 & 0.015 & 0.076 & 0.027 \\
\hline (2.1) & & 1 & 0.107 & 0.046 & 0.017 & 0.051 & 0.008 & 0.042 & 0.022 & 0.016 & 0.068 & 0.026 \\
\hline (2.2) & & & 1 & 0.214 & 0.088 & 0.059 & 0.135 & 0.158 & 0.068 & 0.110 & 0.271 & 0.074 \\
\hline (2.3) & & & & 1 & 0.034 & 0.170 & 0.040 & 0.028 & 0.062 & 0.070 & 0.022 & 0.052 \\
\hline (2.4) & & & & & 1 & 0.078 & 0.023 & 0.022 & 0.007 & 0.026 & 0.065 & 0.005 \\
\hline (2.5) & & & & & & 1 & 0.071 & 0.147 & 0.065 & 0.055 & 0.200 & 0.079 \\
\hline (2.6) & & & & & & & 1 & 0.035 & 0.032 & 0.018 & 0.044 & 0.035 \\
\hline (2.7) & & & & & & & & 1 & 0.036 & 0.041 & 0.048 & 0.030 \\
\hline (2.8) & & & & & & & & & 1 & 0.029 & 0.094 & 0.006 \\
\hline (3) & & & & & & & & & & 1 & 0.089 & 0.032 \\
\hline (4) & & & & & & & & & & & 1 & 0.091 \\
\hline (5) & & & & & & & & & & & & 1 \\
\hline
\end{tabular}



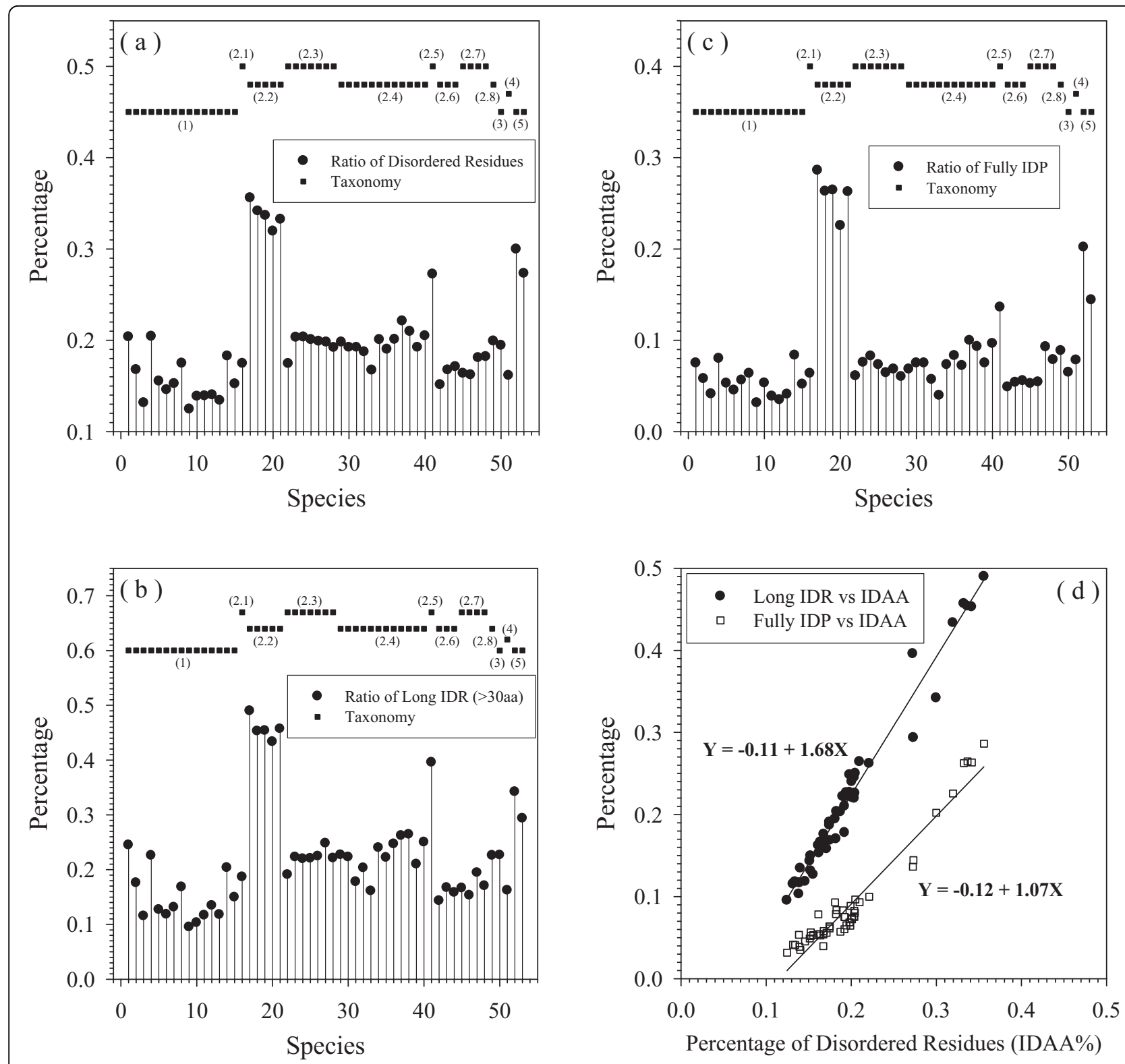

Figure 5 Various measures of intrinsic disorder content in $\mathbf{5 3}$ species: (a), Ratio of disordered residues in each species; (b), Percentage of proteins with long disordered regions (>30aa) in each species; (c), Ratio of fully disordered proteins in each species. In all figures above, the $X$-axis is the index number of each species. Filled squares indicate the taxonomy of archaea with similar species together and on the same level. (1), (3)-(5) indicate species in four phyla: Crenarchaeota, Korarchaeota, Nanoarcgaeota, and Thaumarchaeota. (2.1) - (2.8) are eight different classes in the phylum of Euryarchaeota. (d), Correlation among various disordered contents. X-axis: the ratio of disordered residues. Y-axis: percentage of proteins with long disordered regions and percentage of fully disordered proteins, accordingly.

signaling and regulation to counteract the high ion concentration. Thermococci tend to have more stable ordered proteins to resist the influence of high environment temperature.

Figure 5(d) represents the relation among the various means used to evaluate the disorder content in the Archaea proteomes. As shown by this plot, the total number of disordered residues, the amount of long IDRs, and the number of wholly disordered IDPs are well-correlated at the proteome level. In other words, this analysis clearly shows that the proteomes with the larger total amount of disordered residues typically contain a larger amount of long disordered regions and larger number of wholly disordered proteins.

To better understand the distribution of wholly disordered proteins in various Archaea proteomes, we further analyzed their $\mathrm{CH}-\mathrm{CDF}$ phase space. The averaged data for all 5 Archaea phyla and 8 classes of Euryarchaeota 
are shown in Figure 6(a) and Figure 6(b), respectively. As shown by Figure 6(a), the averaged $\mathrm{CH}$-distance values are decreasing, while averaged CDF-distances are increasing in the order of Thaumarchaeota, Euryarchaeota, Nanoarchaeota, Korarchaeota, and Crenarchaeota. This trend indicates the correspondingly decreased content of charged residues, increased content of structured-promoting residues, or a combination of these two factors. Error bars give the estimation of the distribution of all the relevant distances for that species. Apparently, larger error bars correspond to a broader distribution. Hence, while the distributions of CDF-distances are similar among all five phyla, Thaumarchaeota has broadest distribution of the $\mathrm{CH}$-distances. In Figure 6(b), Halobacteria and Methanopyri have obviously larger averaged $\mathrm{CH}$-distance and smaller
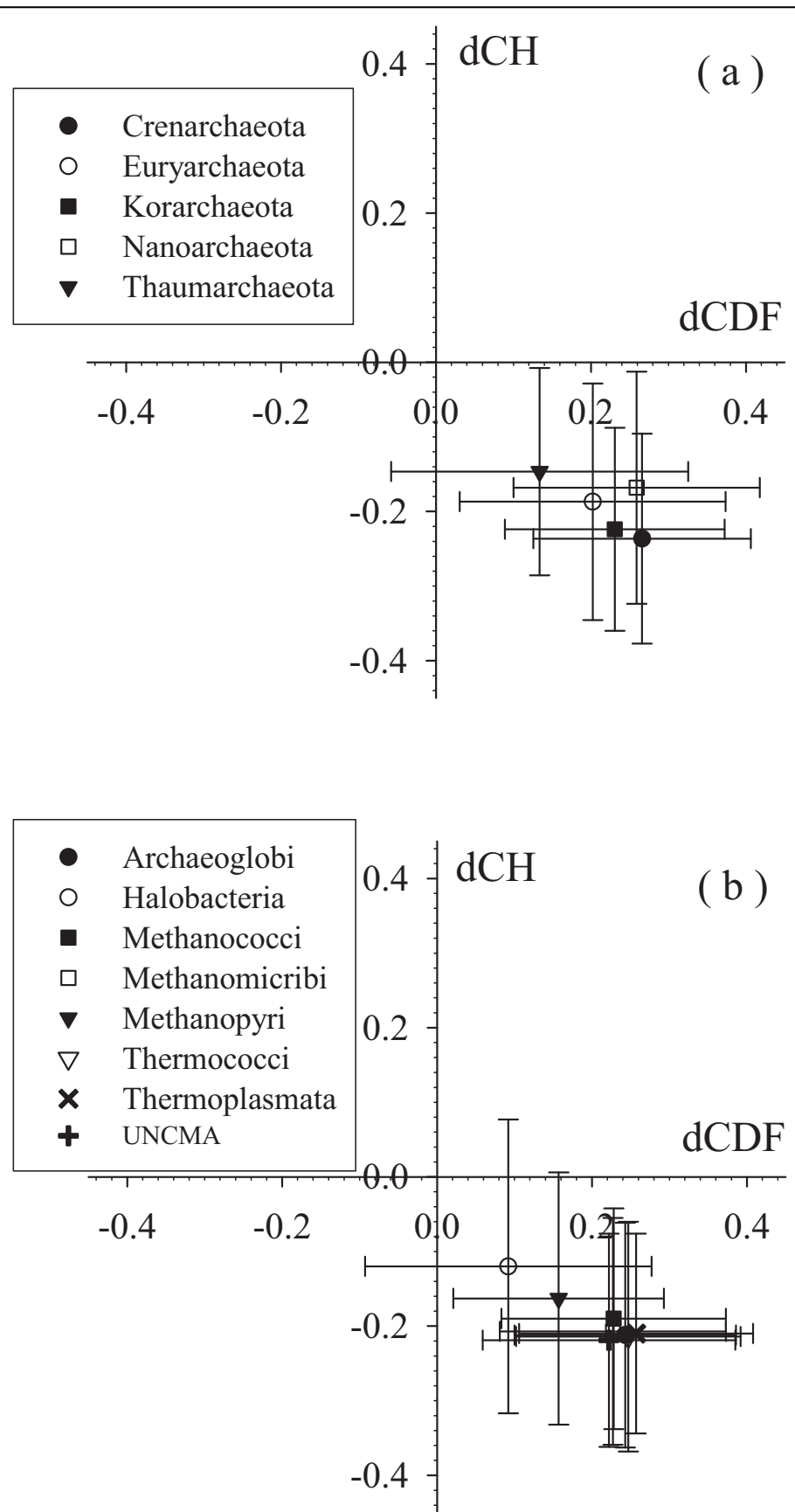

Figure 6 Averaged CH-CDF plots for (a) five phyla and (b) eight classes in Euryarchaeota. Various symbols indicate the averaged values of $\mathrm{CH}$ - and CDF-distances of all proteins in that species. Error bars are calculated from the root mean square deviation of the same set of proteins. 
averaged CDF-distance than other 5 classes. Halobacteria has much broader distribution of the CDF-distances. The other 5 Thaumarchaeota classes have somewhat overlapped values.

The abundance of intrinsically disordered proteins in various Archaea proteomes is further illustrated by Figures S1 and S2 (see additional file 1) which represent $\mathrm{CH}-\mathrm{CDF}$ plots for Archaea phyla (Additional file 1, Figure S1) and for the 8 Euryarchaeota classes (Additional file 1, Figure S2). In these plots, each spot corresponds to a single protein and its coordinates are calculated as a distance of this protein from the boundary in the corresponding $\mathrm{CH}$-plot (Y-coordinate) and an averaged distance of the corresponding CDF curve from the boundary (X-coordinate). Positive and negative $\mathrm{Y}$ values correspond to proteins which, according to $\mathrm{CH}$-plot analysis, are predicted to be natively unfolded or compact, respectively. Whereas positive and negative $\mathrm{X}$ values are attributed to proteins that, by the CDF analysis, are predicted to be ordered or intrinsically disordered, respectively. Therefore, each plot contains four quadrants: (-, -) contains proteins predicted to be disordered by $\mathrm{CDF}$, but compact by $\mathrm{CH}$-plot (i.e., proteins with molten globule-like properties); (-, +) includes proteins predicted to be disordered by both methods (i.e., random coils and pre-molten globules); (+, -) contains ordered proteins; $(+,+)$ includes proteins predicted to be disordered by $\mathrm{CH}$-plot, but ordered by the $\mathrm{CDF}$ analysis. Both figures also give the number of proteins found in the corresponding quadrants. Analysis of the $(-,-)$ and $(-,+)$ quadrants in Additional file 1, Figure S1 shows that the majority of the wholly disordered proteins from Crenarchaeota, Korarchaeota, Euryarchaeota, and Thaumarchaeota likely possess molten globule-like properties. In contrast, the proteomes of Nanoarchaeota are generally characterized by a more balanced distribution between compact and extended disordered proteins. The analysis of these two quadrants in the Euryarchaeota phylum (see Figure S2 in Additional file 1) shows that proteomes of Archaeoglobi, Methanococci, Methanomicrobia, Methanopyri, Thermococci, and UNCMA all have more molten globulelike IDPs than extended IDPs. The situation is reversed in Halobacteria and Thermoplasmata which are predicted to have more extended IDPs than native molten globules.

\section{Intrinsic disorder and habitats of the Archaea}

In order to understand a correlation between the abundance of IDPs in various Archaea and their natural habitats, we searched for several environmental characteristics, such as optimal salinity, optimal $\mathrm{pH}$ and optimal temperature (see Table S1 in Additional file 1). Figure 7 represents the disorder content in the Archaea
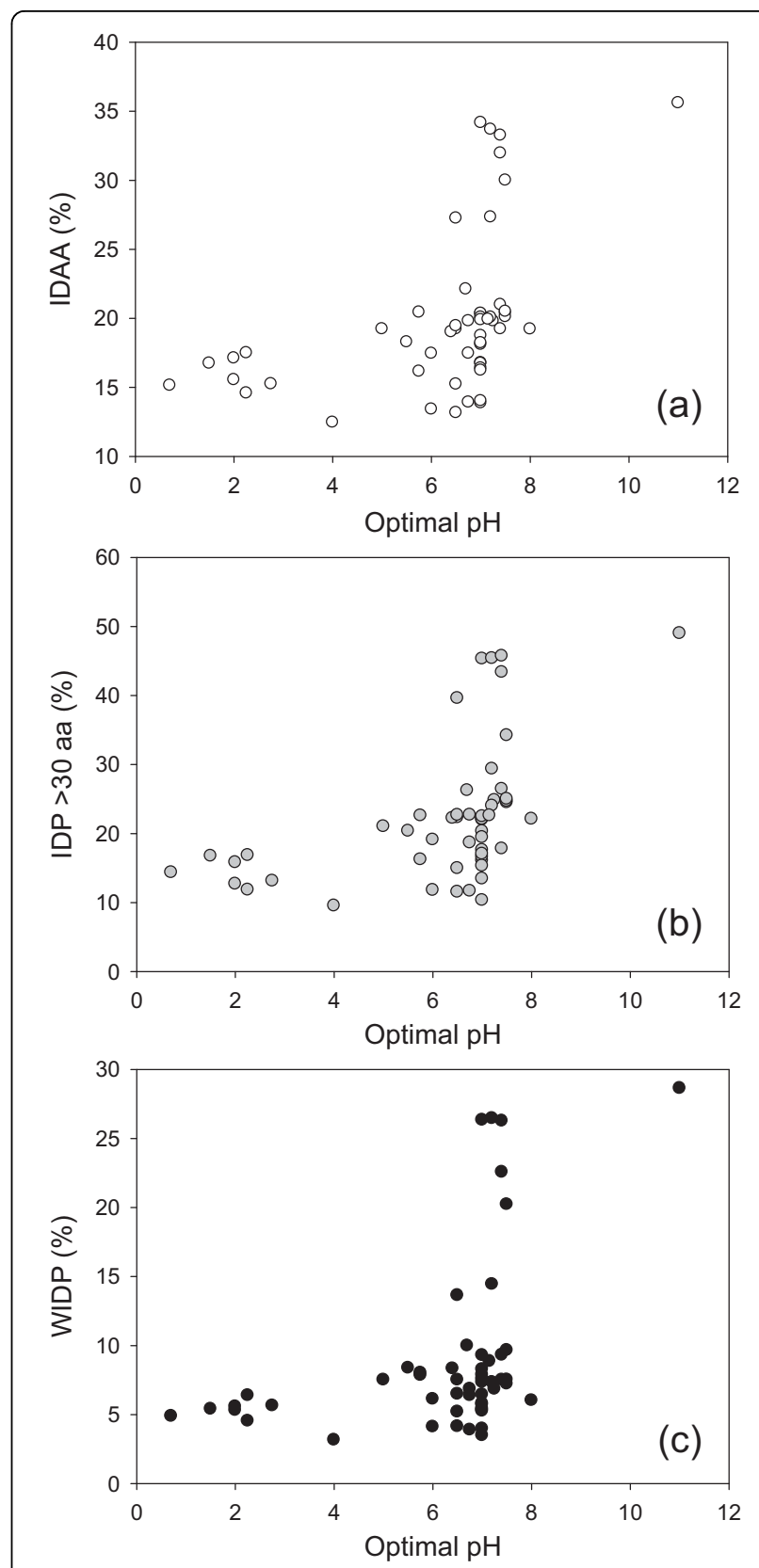

Figure 7 The distribution of intrinsic disorder content in the Archaea as a function of optimal pH. Three measures of intrinsic disorder: (a) overall percentage of intrinsically disordered residues (IDAA); (a) percentage of proteins with long disordered regions (IDP >30 aa); (c) and the percentage of wholly disordered proteins (WIDP).

as a function of optimal $\mathrm{pH}$. We used three measures of intrinsic disorder, overall percentage of intrinsically disordered residues (IDAA), percentage of proteins with long disordered regions (IDP $>30 \mathrm{aa}$ ), and percentage of wholly disordered proteins (WIDP). Figure 7 shows that the organisms living in habitats with $\mathrm{pH}$ values close to neutral (ranging from $\mathrm{pH} 6.0$ to $\mathrm{pH}$ 8.0) possess very 
large disorder diversity. On the other hand, all the acidophilic Archaea are characterized by the relatively low abundance of intrinsic disorder, whereas the only alkaliphile, Natronomonas pharaonis, has the highest content of intrinsic disorder as measured by the overall number of disordered residues, the number of long disordered regions and the number of completely disordered proteins in its proteome.

The dependence of the disorder content in the Archaea on the salinity of their habitats is shown in Figure 8 , which clearly shows that all the halophiles are characterized by a very large amount of disorder. This observation supports the notion that extra IDPs are likely to be needed to these species to help them dealing with the high concentrations of ions in their environment. Of special interest is a Cenarchaeum symbiosum, which live in the low salinity environments but is still characterized by high abundance of IDPs (see circled point in Figure 8). The peculiar difference of this organism is that this symbiotic archaeon is a psychrophilic crenarchaeon which inhabits a marine sponge. Another peculiar organism with large amount of disorder is Methanopyrus kandleri (see squared point in Figure 8). Although the living environment of this archaeon is characterized by the normal salinity, it is known to grow at the hostile conditions of very high temperatures (between 100 and $110^{\circ} \mathrm{C}$ ) and high hydrostatic pressure. In fact, Methanopyrus kandleri was isolated from the overheated walls of the black smoker from the Gulf of California found at the depth of $2000 \mathrm{~m}$.

Finally, Figure 9 represents the dependence of the amount of disorder in various Archaea as a function of temperature of their habitats. Figure 9 shows that generally there is a slight negative correlation between these two parameters. The obvious exceptions from this trend are halophilic proteomes (see squared points in Figure 9), as well as already discussed Methanopyrus kandler (see triangled point in Figure 9) and Cenarchaeum symbiosum (see circled point in Figure 9).

Altogether, data represented in Figure 7, 8 and 9 show that the amount of intrinsic disorder in Archaea correlates with the peculiarities of their environment. Generally, organisms prospering at the extremely hazardous conditions (such as very high temperature, highly alkaline $\mathrm{pH}$, very high salinity) are enriched in IDPs. Of special interest is the fact that various environmental factors possess different strength in promoting intrinsic disorder. For example, organisms living in an extremely hostile, highly acidic environment possess relatively low amount of disorder. Even proteins of the archaeon Picrophilus torridus which lives in and grows at the lowest $\mathrm{pH}$ values known among all organisms, including conditions such as $1 \mathrm{M}$ sulfuric acid, effectively grows only below pH 3.5 (optimal pH $=0.7$ ) and possesses
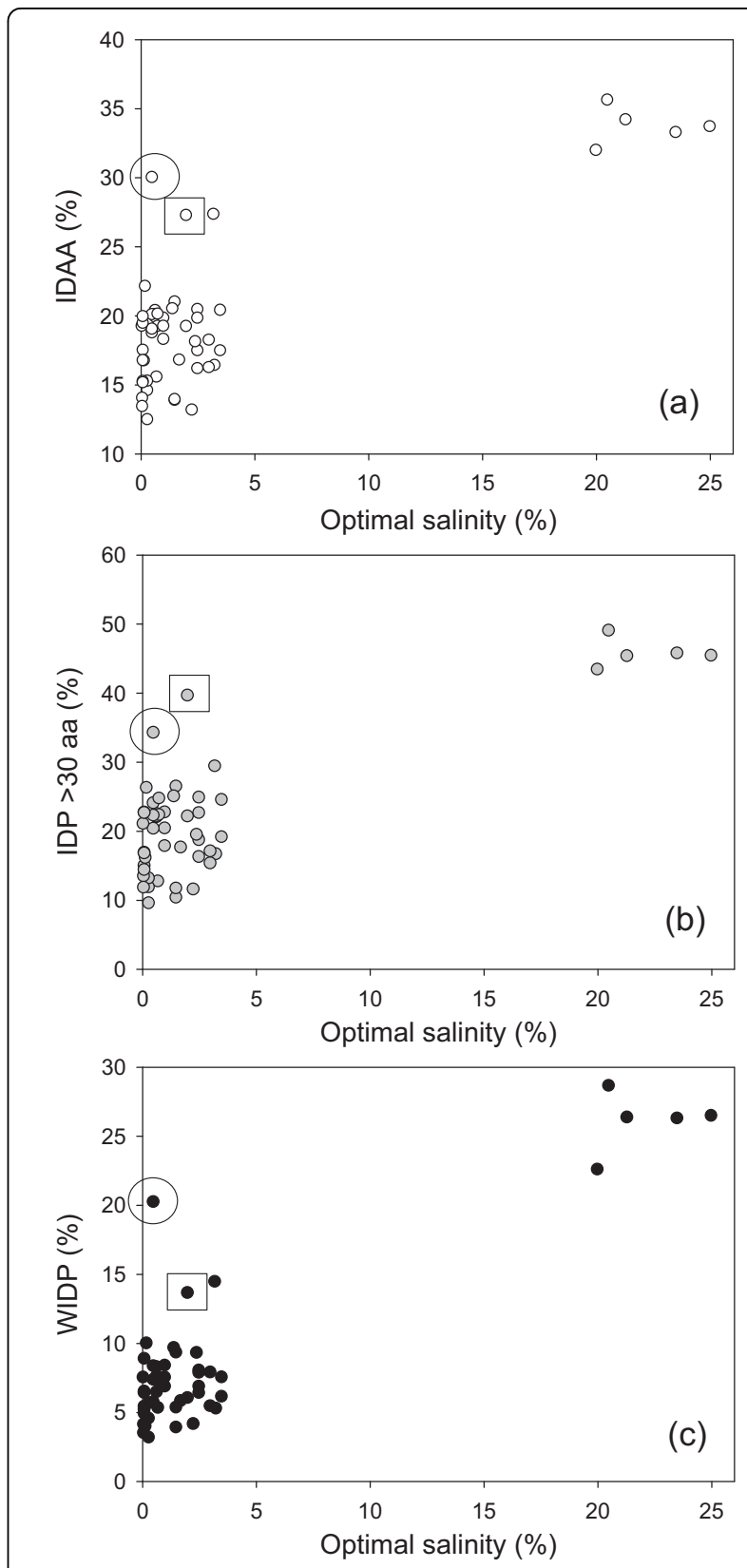

Figure 8 The distribution of intrinsic disorder content in the Archaea as a function of salinity of their habitats. Three measures of intrinsic disorder: (a) overall percentage of intrinsically disordered residues (IDAA); (b) percentage of proteins with long disordered regions (IDP >30 aa); (c) and the percentage of wholly disordered proteins (WIDP).

significant growth even at a $\mathrm{pH}$ around 0 , contain only $15 \%$ of disordered residues. On the other hand, among the most prominent enhancers of intrinsic disorder are habitats with very high salinity and alkaline $\mathrm{pH}$. The combination of extremely high temperature and high hydrostatic pressure potentially also represent environment favoring intrinsic disorder. Another strong 

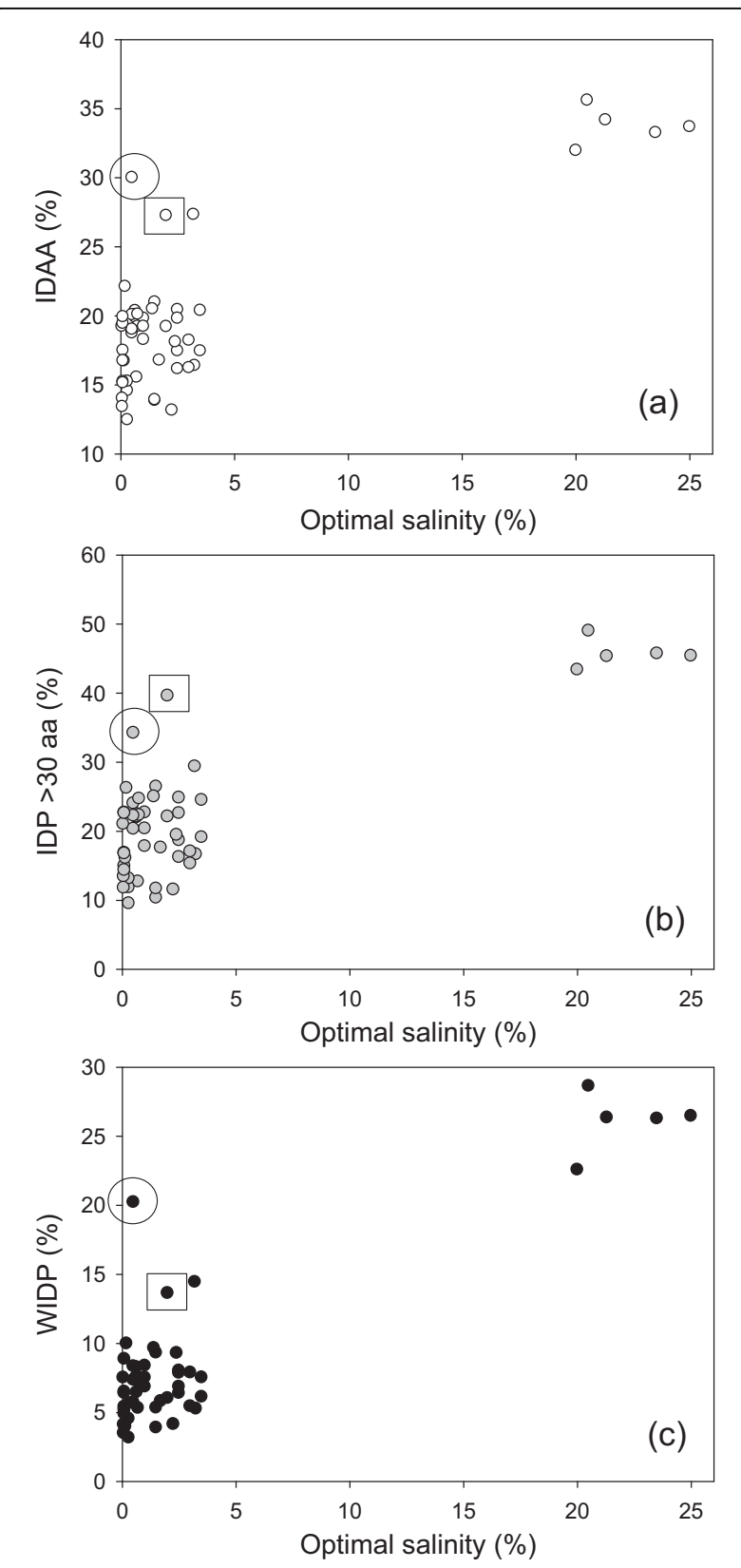

Figure 9 The distribution of intrinsic disorder content in the Archaea as a function of temperature of their habitats. Three measures of intrinsic disorder: (a) overall percentage of intrinsically disordered residues (IDAA); (b) percentage of proteins with long disordered regions (IDP $>30 \mathrm{aa}$ ); (c) and the percentage of wholly disordered proteins (WIDP).

disorder-promoting factor is the symbiotic life style. All this suggests that intrinsic disorder can be used by the Archaean organisms to better adjust for their harsh living conditions or, in the case the symbiotic microbes, for the accommodation to the conditions inside the sponge and for better communication with the cells of the host.
Intrinsic disorder and function of the Archaea proteins

Earlier studies clearly showed that protein intrinsic disorder is of great functional importance [27,31,32]. Proteins often contain one or more functional domains, different combinations of which give rise to the diverse range of proteins found in nature. It has been recognized that the identification of domains that occur within proteins can therefore provide insights into their function. To find a correlation between intrinsic disorder and function in the Archaea proteins we analyzed the abundance of intrinsic disorder in the Pfam database, which contains information on protein domains and families and uses hidden Markov models and multiple sequence alignments to identify members of its families emphasizing the evolutionary conservation of protein domains [58-60]. Each curated family in Pfam is represented by a seed and full alignment. The seed contains representative members of the family, while the full alignment contains all members of the family as detected with a profile hidden Markov model (HMM) [58]. Since Pfam represent an important tool for understanding protein structure and function and since this database contains large amount of information on functional domains, the Archaea seed domains in the version 23.0 of the Pfam database were analyzed. There are more than 12,700 Pfam domain seeds of the Archaean origin, which vary in length from 16 to 1462 residues, whereas the mean length of the Archaean Pfam domains is 156 residues (Figure S3, in Additional file 1).

Figure S4 in Additional file 1 ) shows that intrinsic disorder is rather abundant in the Archaean Pfam seed domains. On average, $15.4 \%$ of residues in functional domains of the Archaea origin are predicted to be disordered (Figure S4A). In fact, several Archaean domains are completely disordered and only $\sim 2,000$ domains are completely devoid disordered regions (Figure S4A, additional file 1). Many of the domains contain at least one disordered region, with some domains possessing more than 10 disordered regions (Figure S4B, Additional file 1). The length of disordered regions in the domains varies from 1 to 201 residues (Figure S4C, Additional file 1).

The intrinsic disorder propensity among the Archaean members of the Pfam database is further illustrated by Figure S5 (see Additional file 1) which represents a three dimensional plot of total percent disorder, disordered region length (where there are up to 26 disordered regions per domain), and domain length for all Archaea seed domains in version 23.0 of the Pfam database. Figure S6 (see Additional file 1) represents the data as a three dimensional plot of the log of the number of disordered regions, the log of the number of disordered residues, and the log of the percent disorder in each of all of the Archaea seed domains in version 23.0 of the Pfam database. In this plot, all domains with one 
disordered region are represented in the cluster on the left. Domains with between ten and 26 disordered regions are represented at 1 and above on the right. Domains with no disordered regions are not included. These figures suggest that there is a weak correlation between percent disorder and disordered region length, but no correlation between these observations and Pfam domain length.

Therefore, data presented here clearly show that many functional domains in Archaea are predicted to contain various amounts of disordered residues. Table 2 lists several domains with high disorder content and shows that these intrinsically disordered domains play crucial roles in interaction with RNA, DNA, and proteins and are important for recognition, regulation and signal transduction. In other words, Archaean disordered domains fulfill functions similar to those of prokaryotic and eukaryotic proteins $[27,31,32]$.

Further evidence on the biological importance of intrinsic disorder found in the archaea proteins is given by Figure 10 which illustrates predicted and experimentally verified disordered regions in the Archaea translation initiation factor 2 (aIF2). aIF2 facilitates translation by recruiting methonyl-tRNA to the ribosome and aiding in the identification of the start codon, hydrolyzing GTP in the process [61]. aIF2 consists of three subunits: regulatory $\alpha$ and $\beta$ subunits, and the GTP hydrolyzing $\gamma$ subunit. aIF $2 \beta$ of Sulfolobus solfataricus is an intrinsically disordered protein consisting of both ordered and disordered regions (Figure S5, see additional file 1). The $\mathrm{N}$-terminus of aIF2 $\beta$ has been shown to be disordered [62] and also in the homologous protein from Methanobacterium thermoautotrophicum[63]. However, this region is responsible for mediating binding to aIF2 $\gamma$ through a MoRF-type interaction. This interaction is shown in Figure 10, where the aIF2 $\gamma$ binding region corresponds to a local prediction of order in the $\mathrm{N}$-terminus of aIF $2 \beta$. Additionally, aIF $2 \beta$ has a central core domain and a $\mathrm{C}$-terminal zinc finger domain, both of which play roles in RNA recognition [64]. Presumably the MoRF interaction provides flexibility to these domains to facilitate molecular recognition [64].

\section{Phylogenetic tree of the Archaea and intrinsic disorder}

Figure 11 overlaps the disorder content of various species with the Archaea phylogenetic tree. In this figure, colors of the branches correspond to the abundance of disordered residues in the corresponding species. Clearly, as indicated by the same color on the related branches of the tree, proteomes belonging to the same phylum typically have comparable contents of disordered residues in their proteins. For example, all the species in the Crenarchaeota phylum are characterized by the relatively small amount of disordered proteins, containing in average $\sim 15 \%$ intrinsically disordered amino acids (IDAA). The correlation is even stronger for species belonging to the same order, where the amount of intrinsic disorder remains relatively constant. For example, all the species from the Thermoproteales order have low IDAA content (less than 14\%). This value increases to $\sim 16 \%$ in various Sulfolobales and further increases to up to 20\% in Desulfurococcales.

Analysis of the Eutyarchaeota phylum also revealed a comparable trend in the distribution of IDAA. Here, all the members of the Archaeoglobi, Halobacteria, Methanococci, and Methanomicrobia, contain a relatively high amount of disorder (ranging from $\sim 16$ to $\sim 36 \%)$. Once again, each Eutyarchaeota class was characterized by the relatively uniform distribution of disorder: for example, the amount of disorder in the Halobacteria ranged from 32 to $35.6 \%$, whereas Methanomicrobia contained from 16.7 to $20.1 \%$ IDAA.

Interestingly, Figure 11 provides some insights into the correlation between the evolution of Archaea and the intrinsic disorder distribution in these organisms. In the Methanococci - Methanopyri - Thermococci branch, Methanoccoci deviated first from other Archaea with the high IDAA of $\sim 20 \%$. Later on, Methanopyri left the main branch with ratio of IDAA up to $27 \%$. Although Thermococci generally possess a relatively low

Table 2 Illustrative highly disordered Pfam domains of archaean origin

\begin{tabular}{|c|c|c|c|}
\hline Name & Domain & Description & $\% \mathrm{D}$ \\
\hline NOP10_SULSO & $1-53$ & nucleolar protein essential for normal 18S rRNA production and rRNA pseudouridylation & 41 \\
\hline PUR2_METJA & $1-102$ & related to the $\mathrm{N}$-terminal domain of biotin carboxylase/carbamoyl phosphate synthetase & 42 \\
\hline O27142_METTH & $17-302$ & tldD and pmbA proteins, found to suppress mutations in letD and inhibit of DNA gyrase & 44 \\
\hline Y2068_ARCFU & $10-100$ & transmembrane region of Cytochrome $C$ biogenesis protein believed to bind double-stranded DNA & 64 \\
\hline RF1_METTH & 2-137 & eRF1 stops protein biosynthesis by recognising stop codons and stimulating peptidyl-tRNA hydrolysis & 81 \\
\hline Y2677_METMA & $7-59$ & CsbD, a bacterial general stress response protein & 100 \\
\hline MTPE_SULTO & $1-56$ & epsilon subunit of the ATP synthase, a potent inhibitor of ATPase activity & 100 \\
\hline Q48297_HALSA & 295-353 & helical bundle domain, homodimer interface of the signal transducing histidine kinase family & 100 \\
\hline Q8TTT9_METAC & $235-302$ & NosD, a periplasmic protein thought to insert copper into the exported reductase apoenzyme & 100 \\
\hline
\end{tabular}




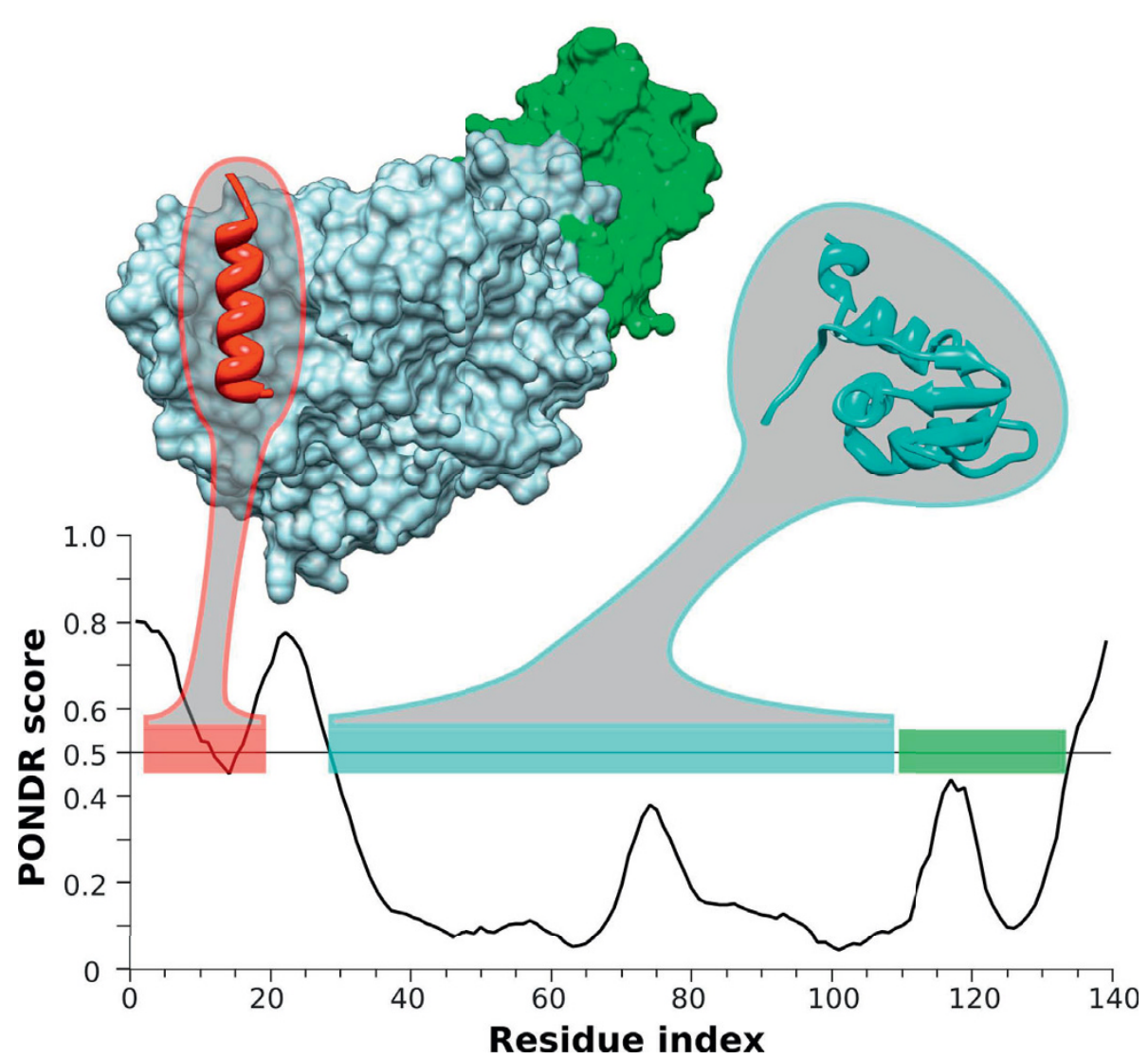

Figure 10 PONDR $^{\oplus}$ prediction and experimentally solved structure of alF2 $\boldsymbol{\beta}$ from Sulfolobus solfataricus. The PONDR ${ }^{\circledR}$ VSL2 prediction is given in the plot, where scores greater than 0.5 are predictions of disordered residues and scores less then 0.5 are predictions of ordered residues. Horizontal bars represent regions with known structure, or are likely to be structured, which are (from $\mathrm{N}$ - to $\mathrm{C}$ - termini): the alF $2 \gamma$ binding MoRF region (red bar), the core domain (cyan bar), and the C-terminal zinc finger domain (green bar). Additionally, structures of the alF $2 \gamma$-binding MoRF region (red ribbon) bound to alF $2 \gamma$ (blue surface) and alF2 $\alpha$ (green surface), and of the core domain (cyan ribbon) are shown (coordinates from PDB entries 2QN6 and 2NXU, respectively).

amount of disorder in comparison with other members of this branch, Pyrococcus horikoshi being close to Methanoccoci and Methanopyri, is characterized by the highest disorder content ( $18 \%)$, whereas other members of this class are close to the Crenarchaeota phylum and are correspondingly characterized by the lower amount of disorder $(\sim 16 \%)$. In the Crenarchaeota phylum, where the majority of members are characterized by the disorder content ranging from 12.5 to $14.0 \%$, Hyperthermus butylicus, Thermofilum pendens, and Aeropyrum pernix, all located in the close branches, which deviated from the major branch relatively late, possess 17-20\% IDAA. Therefore, these observations suggest that in general the amount of disorder increases with evolution. There is only one counter-example to this rule, which is found in the class of Methanoicrobia, where Methanocorpusculum labreanum is not the oldest species in that class, but has an apparently lower content of disordered residues than other older species.

\section{Need for the habitat-specific disorder predictors}

Data presented in this paper indicate that there is a correlation between the amount of intrinsic disorder in a proteome of a given archaeaon and the peculiarities of its habitat. Intriguingly, not only the amounts of intrinsic disorder in the proteomes of archaea prospering in various hostile conditions are different and depend on the environmental peculiarities, proteins of these proteomes possess a number of environment-dependent characteristic features (e.g., specific biases in the amino acid compositions). Data shown in Figure 4(b) suggest that these sequence features are unique and different enough to potentially allow the development of habitatspecific predictors of intrinsic disorder for archaea. In fact, this hypothesis is in agreement with our recent study of integral transmembrane proteins which revealed that the disordered regions from helical bundle integral membrane proteins, those from $\beta$-barrel integral membrane proteins, and those from water soluble 


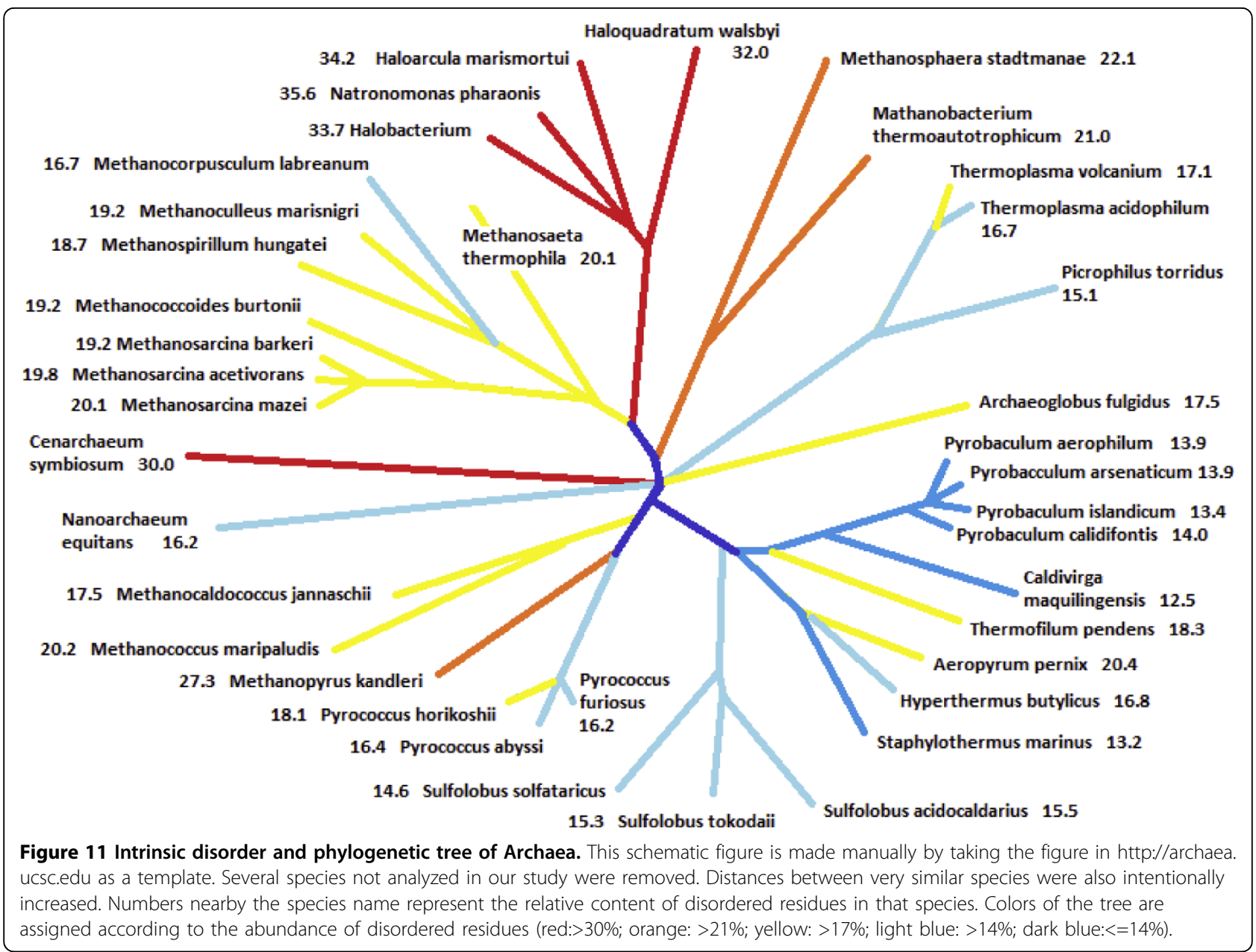

proteins all exhibit statistically distinct amino acid compositional biases [54]. Although the detailed analysis showed that, despite these differences in composition, current algorithms make reasonably accurate predictions of disorder for these membrane proteins, it has been proposed that developing new predictors that make use of data from disordered regions in helical bundles and beta barrels will likely lead to significantly more accurate disorder predictions for these two classes of integral membrane proteins [54].

\section{Conclusions}

In this paper, we systematically analyzed the abundance of intrinsically disordered proteins and the intrinsically disordered regions in 53 Archaea species, which are grouped into 5 phyla and 11 classes. The size of proteomes of these species extends from 536 proteins to 4,234 proteins with the majority of Archaea having around 2,000 proteins. The abundance of intrinsic disorder was species-dependent. The averaged ratio of predicted disordered residues varied from $\sim 14 \%$ in Thermoproteales to $\sim 34 \%$ in Halobacteria. Further analysis based on amino acid composition profiles confirmed large differences between various species. However, even between closely related species, the content of disordered residues changed greatly. Staphylothermus marinus and Ignicoccus hospitalis are two species in the same order Desulfurococcales of the Thermoprotei class in the Crenarchaeota phylum, but Ignicoccus hospitalis had 7\% more disordered residues than Staphylothermus marinus. In Thermoproteales of the same phylum and class, Thermofilum pendens had around 6\% more disordered residues than Caldivirga maquilingensis.

The relation between various measures of disordered content; i.e., the relative content of disordered residues, the content of proteins containing long disordered regions, and the number of fully disordered proteins was also analyzed. All of these measures of intrinsic disorder content are shown to be linearly correlated with each other at the genome level. This relationship provided important information for the general understanding of disordered proteins. However, more computational experiments are needed to verify this conclusion since this result comes from the predictions on 53 species. 
Next we analyzed the correlation between the abundance of intrinsic disorder in a given Archaeaon and peculiarities of its habitat. Since many of the Archaea are know to survive at extremely harsh environmental conditions, this exercise was interesting and important. Analysis revealed that various environmental factors possessed different strength in promoting intrinsic disorder. The most prominent enhancers of intrinsic disorder were habitats with very high salinity, alkaline $\mathrm{pH}$ or characterized by the combination of extremely high temperature and high hydrostatic pressure. Symbiotic archaeaon, Cenarchaeum symbiosum, was also shown to contain high level of intrinsically disordered proteins. This clearly suggested that Archaea generally utilized intrinsic disorder for adjustment to their living conditions.

Many functional Pfam seed domains of the Archaea origin were shown to possess various levels of intrinsic disorder. Only about $15 \%$ of these functional domains were completely devoid of disorder. Disordered Pfam domains were involved in various crucial functions, such as signaling, regulation and interaction with nucleic acids and proteins, suggesting that similar to proteins from other domains of life, intrinsic disorder is heavily used by the Archaean proteins in their functions.

We also designed a new protocol by combining disorder predictions and phylogenetic tree to show the correlation between evolutionary development and disorder. A gradual increase in the amount of intrinsic disorder with the evolution of species was observed. More interestingly, the ratios of disordered residues can also be reduced in the process of evolution. Based on the hypothesis that disordered proteins are crucial for signaling and regulation, it is not difficult to understand the need for an increased level of intrinsic disorder in newly evolved species. However, data for Methanocorpusculum labreanum raised the question on whether the decreased amount of intrinsic disorder found in this organism can be considered as an atavism. In fact, one of the Methanocorpusculum labreanum paralogues, Methanosaete thermophila, has a smaller proteome but higher content of disordered residues, whereas two other paralogues, Methanoculleus marisnigri and Methanospirillum hungatai, have a higher content of disordered residues and larger proteomes.

Additional file 1:

\section{Acknowledgement}

This work was supported in part by the grants R01 LM007688-01A1 (to A.K.D and V.N.U.) and GM071714-01A2 (to A.K.D and V.N.U.) from the National Institute of Health, the grant EF 0849803 (to A.K.D and V.N.U.) from the National Science Foundation, and the Program of the Russian Academy of Sciences for the "Molecular and Cellular Biology" (to V.N.U.). We gratefully acknowledge the support of the IUPUI Signature Centers Initiative.
This article has been published as part of BMC Systems Biology Volume 4 Supplement 1, 2010: Proceedings of the ISIBM International Joint Conferences on Bioinformatics, Systems Biology and Intelligent Computing (IJCBS). The full contents of the supplement are available online at http://www.biomedcentral.com/1752-0509/4?issue=S1.

\section{Author details}

${ }^{1}$ Center for Computational Biology and Bioinformatics, Indiana University School of Medicine, Indianapolis, IN 46202, USA. ${ }^{2}$ Institute for Intrinsically Disordered Protein Research, Indiana University School of Medicine, Indianapolis, IN 46202, USA. ${ }^{3}$ Department of Biomedical Informatics, Uniformed Services University, Bethesda, MD 20814, USA. ${ }^{4}$ Center for Computational Biology and Bioinformatics, Indiana University School of Informatics, Indianapolis, IN 46202, USA. ${ }^{5}$ Institute for Biological Instrumentation, Russian Academy of Sciences, 142290 Pushchino, Moscow Region, Russia.

\section{Authors' contributions}

BX, RWW, and CJO designed and implemented experiments. All authors analyzed results. VNU developed strategy and provided advice. Each author contributed equally in writing the paper. All authors read and approved the final manuscript.

\section{Competing interests}

The authors declare that they have no competing interests.

Published: 28 May 2010

\section{References}

1. Woese CR, Kandler O, Wheelis ML: Towards a natural system of organisms: proposal for the domains Archaea, Bacteria, and Eucarya. Proc Natl Acad Sci U S A 1990, 87(12):4576-4579.

2. Woese CR: Bacterial evolution. Microbiol Rev 1987, 51(2):221-271.

3. Woese CR: Interpreting the universal phylogenetic tree. Proc Natl Acad SCi U S A 2000, 97(15):8392-8396.

4. Schnabel R, Thomm M, Gerardy-Schahn R, Zillig W, Stetter KO, Huet J: Structural homology between different archaebacterial DNA-dependent RNA polymerases analyzed by immunological comparison of their components. Embo J 1983, 2(5):751-755.

5. Kimura M, Arndt E, Hatakeyama T, Hatakeyama T, Kimura J: Ribosomal proteins in halobacteria. Can J Microbiol 1989, 35(1):195-199.

6. Auer J, Lechner K, Bock A: Gene organization and structure of two transcriptional units from Methanococcus coding for ribosomal proteins and elongation factors. Can J Microbiol 1989, 35(1):200-204.

7. Forterre P: Archaea: what can we learn from their sequences? Curr Opin Genet Dev 1997, 7(6):764-770.

8. Makarova KS, Aravind L, Galperin MY, Grishin NV, Tatusov RL, Wolf YI, Koonin EV: Comparative genomics of the Archaea (Euryarchaeota): evolution of conserved protein families, the stable core, and the variable shell. Genome Res 1999, 9(7):608-628.

9. Olsen GJ, Woese CR: Archaeal genomics: an overview. Cell 1997, 89(7):991-994

10. Rivera MC, Jain R, Moore JE, Lake JA: Genomic evidence for two functionally distinct gene classes. Proc Natl Acad Sci U S A 1998, 95(11):6239-6244.

11. Pace NR: A molecular view of microbial diversity and the biosphere. Science 1997, 276(5313):734-740.

12. Matte-Tailliez $\mathrm{O}$, Brochier $\mathrm{C}$, Forterre $\mathrm{P}$, Philippe $\mathrm{H}$ : Archaeal phylogeny based on ribosomal proteins. Mol Biol Evol 2002, 19(5):631-639.

13. Woese CR, Fox GE: Phylogenetic structure of the prokaryotic domain: the primary kingdoms. Proc Natl Acad Sci U S A 1977, 74(11):5088-5090.

14. Hugenholtz P: Exploring prokaryotic diversity in the genomic era. Genome Biol 2002, 3(2):REVIEWS0003.

15. Huber H, Hohn MJ, Rachel R, Fuchs T, Wimmer VC, Stetter KO: A new phylum of Archaea represented by a nanosized hyperthermophilic symbiont. Nature 2002, 417(6884):63-67.

16. Elkins JG, Podar M, Graham DE, Makarova KS, Wolf Y, Randau L, Hedlund BP, Brochier-Armanet C, Kunin V, Anderson I, et al: A korarchaeal genome reveals insights into the evolution of the Archaea. Proc Natl Acad Sci U S A 2008, 105(23):8102-8107. 
17. Brochier-Armanet C, Boussau B, Gribaldo S, Forterre P: Mesophilic Crenarchaeota: proposal for a third archaeal phylum, the Thaumarchaeota. Nat Rev Microbiol 2008, 6(3):245-252.

18. DeLong EF, Pace NR: Environmental diversity of bacteria and archaea. Syst Biol 2001, 50(4):470-478.

19. Berg IA, Kockelkorn D, Buckel W, Fuchs G: A 3-hydroxypropionate/ 4-hydroxybutyrate autotrophic carbon dioxide assimilation pathway in Archaea. Science 2007, 318(5857):1782-1786.

20. Thauer RK: Microbiology. A fifth pathway of carbon fixation. Science 2007, 318(5857):1732-1733.

21. Mueller-Cajar O, Badger MR: New roads lead to Rubisco in archaebacteria. Bioessays 2007, 29(8):722-724

22. Takai K, Nakamura K, Toki T, Tsunogai U, Miyazaki M, Miyazaki J, Hirayama H, Nakagawa S, Nunoura T, Horikoshi K: Cell proliferation at 122 degrees C and isotopically heavy $\mathrm{CH} 4$ production by a hyperthermophilic methanogen under high-pressure cultivation. Proc Natl Acad Sci U S A 2008, 105(31):10949-10954.

23. Valentine DL: Adaptations to energy stress dictate the ecology and evolution of the Archaea. Nat Rev Microbiol 2007, 5(4):316-323.

24. DeLong EF: Everything in moderation: archaea as 'non-extremophiles'. Curr Opin Genet Dev 1998, 8(6):649-654.

25. Preston CM, Wu KY, Molinski TF, DeLong EF: A psychrophilic crenarchaeon inhabits a marine sponge: Cenarchaeum symbiosum gen. nov., sp. nov. Proc Natl Acad Sci U S A 1996, 93(13):6241-6246.

26. Karner MB, DeLong EF, Karl DM: Archaeal dominance in the mesopelagic zone of the Pacific Ocean. Nature 2001, 409(6819):507-510.

27. Wright $P E$, Dyson HJ: Intrinsically unstructured proteins: re-assessing the protein structure-function paradigm. J Mol Biol 1999, 293(2):321-331.

28. Dunker AK, Lawson JD, Brown CJ, Williams RM, Romero P, Oh JS, Oldfield CJ, Campen AM, Ratliff CM, Hipps KW, et al: Intrinsically disordered protein. J Mol Graph Model 2001, 19(1):26-59.

29. Uversky VN, Gillespie JR, Fink AL: Why are "natively unfolded" proteins unstructured under physiologic conditions? Proteins 2000, 41(3):415-427.

30. Tompa P: The functional benefits of protein disorder. Journal of Molecular Structure-Theochem 2003, 666:361-371.

31. Dunker AK, Brown CJ, Obradovic Z: Identification and functions of usefully disordered proteins. Adv Protein Chem 2002, 62:25-49.

32. Dunker AK, Brown CJ, Lawson JD, lakoucheva LM, Obradovic Z: Intrinsic disorder and protein function. Biochemistry 2002, 41(21):6573-6582

33. Minezaki $Y$, Homma K, Kinjo AR, Nishikawa K: Human transcription factors contain a high fraction of intrinsically disordered regions essential for transcriptional regulation. J Mol Biol 2006, 359(4):1137-1149.

34. Xie H, Vucetic S, lakoucheva LM, Oldfield CJ, Dunker AK, Uversky VN, Obradovic Z: Functional anthology of intrinsic disorder. 1. Biological processes and functions of proteins with long disordered regions. J Proteome Res 2007, 6(5):1882-1898.

35. Romero P, Obradovic Z, Kissinger CR, Villafranca JE, Dunker AK: Identifying Disordered regions in proteins from amino acid sequences. IEEE Int Conf Neural Networks 1997, 1:90-95.

36. Romero P, Obradovic Z, Li X, Garner EC, Brown CJ, Dunker AK: Sequence complexity of disordered protein. Proteins 2001, 42(1):38-48

37. Oldfield CJ, Cheng Y, Cortese MS, Brown CJ, Uversky VN, Dunker AK Comparing and combining predictors of mostly disordered proteins. Biochemistry 2005, 44(6):1989-2000.

38. Oldfield CJ, Cheng Y, Cortese MS, Romero P, Uversky VN, Dunker AK: Coupled folding and binding with alpha-helix-forming molecular recognition elements. Biochemistry 2005, 44(37):12454-12470.

39. Ward JJ, Sodhi JS, McGuffin $\sqcup$, Buxton BF, Jones DT: Prediction and functional analysis of native disorder in proteins from the three kingdoms of life. J Mol Biol 2004, 337(3):635-645.

40. Feng ZP, Zhang $X$, Han $P$, Arora $N$, Anders RF, Norton RS: Abundance of intrinsically unstructured proteins in $P$. falciparum and other apicomplexan parasite proteomes. Mol Biochem Parasitol 2006 150(2):256-267.

41. Obradovic Z, Peng K, Vucetic S, Radivojac P, Brown CJ, Dunker AK Predicting intrinsic disorder from amino acid sequence. Proteins 2003, 53(Suppl 6):566-572

42. Dunker AK, Obradovic Z, Romero P, Garner EC, Brown CJ: Intrinsic protein disorder in complete genomes. Genome Inform Ser Workshop Genome Inform 2000, 11:161-171.

43. [http://www.expasy.ch]
44. Peng K, Radivojac P, Vucetic S, Dunker AK, Obradovic Z: Length-dependent prediction of protein intrinsic disorder. BMC Bioinformatics 2006, 7:208.

45. Cheng Y, Oldfield CJ, Meng J, Romero P, Uversky VN, Dunker AK: Mining alpha-helix-forming molecular recognition features with cross species sequence alignments. Biochemistry 2007, 46(47):13468-13477.

46. Xue B, Oldfield CJ, Dunker AK, Uversky VN: CDF it all: consensus prediction of intrinsically disordered proteins based on various cumulative distribution functions. FEBS Lett 2009, 583(9):1469-1474.

47. Peng K, Vucetic S, Radivojac P, Brown CJ, Dunker AK, Obradovic Z Optimizing long intrinsic disorder predictors with protein evolutionary information. J Bioinform Comput Biol 2005, 3(1):35-60.

48. Dosztanyi Z, Csizmok V, Tompa P, Simon I: The pairwise energy content estimated from amino acid composition discriminates between folded and intrinsically unstructured proteins. J Mol BiOl 2005, 347(4):827-839.

49. Prilusky J, Felder CE, Zeev-Ben-Mordehai T, Rydberg EH, Man O, Beckmann JS, Silman I, Sussman JL: Foldlndex: a simple tool to predict whether a given protein sequence is intrinsically unfolded. Bioinformatics 2005, 21(16):3435-3438.

50. Campen A, Williams RM, Brown CJ, Meng J, Uversky VN, Dunker AK: TOPIDP-scale: a new amino acid scale measuring propensity for intrinsic disorder. Protein Pept Lett 2008, 15(9):956-963.

51. Kyte J, Doolittle RF: A simple method for displaying the hydropathic character of a protein. J Mol Biol 1982, 157(1):105-132

52. Mohan A, Sullivan WJ Jr., Radivojac P, Dunker AK, Uversky VN: Intrinsic disorder in pathogenic and non-pathogenic microbes: discovering and analyzing the unfoldomes of early-branching eukaryotes. Mol Biosyst 2008, 4(4):328-340

53. Vacic V, Uversky VN, Dunker AK, Lonardi S: Composition Profiler: a tool for discovery and visualization of amino acid composition differences. $B M C$ Bioinformatics 2007, 8:211.

54. Xue B, Li L, Meroueh SO, Uversky VN, Dunker AK: Analysis of structured and intrinsically disordered regions of transmembrane proteins. $\mathrm{Mol}$ Biosyst 2009.

55. Radivojac P, lakoucheva LM, Oldfield CJ, Obradovic Z, Uversky VN, Dunker AK: Intrinsic disorder and functional proteomics. Biophys J 2007 92(5):1439-1456

56. Kullback S: The Kullback-Leibler Distance. American Statistician 1987. 41(4):340-340

57. Radivojac P, Obradovic Z, Smith DK, Zhu G, Vucetic S, Brown CJ, Lawson JD Dunker AK: Protein flexibility and intrinsic disorder. Protein Science 2004, 13(1):71-80.

58. Bateman A, Birney E, Cerruti L, Durbin R, Etwiller L, Eddy SR, GriffithsJones S, Howe KL, Marshall M, Sonnhammer EL: The Pfam protein families database. Nucleic Acids Res 2002, 30(1):276-280.

59. Bateman A, Coin L, Durbin R, Finn RD, Hollich V, Griffiths-Jones S, Khanna A Marshall M, Moxon S, Sonnhammer EL, et al: The Pfam protein families database. Nucleic Acids Res 2004, 32(Database issue):D138-141.

60. Finn RD, Tate J, Mistry J, Coggill PC, Sammut SJ, Hotz HR, Ceric G, Forslund K, Eddy SR, Sonnhammer EL, et al: The Pfam protein families database. Nucleic Acids Res 2008, 36(Database issue):D281-288,

61. Bell SD, Jackson SP: Transcription and translation in Archaea: a mosaic of eukaryal and bacterial features. Trends Microbiol 1998, 6(6):222-228.

62. Vasile F, Pechkova $E$, Nicolini $C$ : Solution structure of the beta-subunit of the translation initiation factor alF2 from archaebacteria Sulfolobus solfataricus. Proteins 2008, 70(3):1112-1115.

63. Gutierrez P, Osborne MJ, Siddiqui N, Trempe JF, Arrowsmith C, Gehring K: Structure of the archaeal translation initiation factor alF2 beta from Methanobacterium thermoautotrophicum: implications for translation initiation. Protein Sci 2004, 13(3):659-667.

64. Stolboushkina E, Nikonov S, Nikulin A, Blasi U, Manstein DJ, Fedorov R, Garber M, Nikonov O: Crystal structure of the intact archaeal translation initiation factor 2 demonstrates very high conformational flexibility in the alpha- and beta-subunits. J Mol Biol 2008, 382(3):680-691.

65. Sako $Y$, Nomura N, Uchida A, Ishida $Y$, Morii H, Koga $Y$, Hoaki T, Maruyama T: Aeropyrum pernix gen. nov., sp. nov., a novel aerobic hyperthermophilic archaeon growing at temperatures up to 100 degrees C. Int J Syst Bacteriol 1996, 46(4):1070-1077.

66. Zillig W, Holz I, Janekovic D, Klenk HP, Imsel E, Trent J, Wunderl S, Forjaz VH, Coutinho R, Ferreira T: Hyperthermus butylicus, a hyperthermophilic 
sulfur-reducing archaebacterium that ferments peptides. J Bacterio/ 1990, 172(7):3959-3965.

67. Fiala G, Stetter KO, Jannasch HW, Langworthy TA, Madon J: Staphylothermus marinus sp. nov. represents a novel genus of extremely thermophilic submarine heterotrophic archaebacteria growing up to 98 degree C. Systematic and Applied Microbiology 1986, 8:106-113.

68. Paper W, Jahn U, Hohn MJ, Kronner M, Nather DJ, Burghardt T, Rachel R, Stetter KO, Huber H: Ignicoccus hospitalis sp. nov., the host of 'Nanoarchaeum equitans'. Int J Syst Evol Microbiol 2007, 57(Pt4):803-808.

69. Chen L, Brugger K, Skovgaard M, Redder P, She Q, Torarinsson E, Greve B, Awayez M, Zibat A, Klenk HP, et al: The genome of Sulfolobus acidocaldarius, a model organism of the Crenarchaeota. J Bacteriol 2005, 187(14):4992-4999.

70. Zillig W, Stetter KO, Wunderl S, Schulz W, Priess H, Scholz I: The sulfolobus"caldariella" group: Taxonomy on the basis of the structure of DNAdependent RNA polymerases. Arch Microbiol 1980, 125:259-269.

71. Suzuki T, Iwasaki T, Uzawa T, Hara K, Nemoto N, Kon T, Ueki T, Yamagishi A, Oshima T: Sulfolobus tokodaii sp. nov. (f. Sulfolobus sp. strain 7), a new member of the genus Sulfolobus isolated from Beppu Hot Springs, Japan. Extremophiles 2002, 6(1):39-44.

72. Auernik KS, Maezato Y, Blum PH, Kelly RM: The genome sequence of the metal-mobilizing, extremely thermoacidophilic archaeon Metallosphaera sedula provides insights into bioleaching-associated metabolism. Appl Environ Microbiol 2008, 74(3):682-692.

73. Itoh T, Suzuki K, Sanchez PC, Nakase T: Caldivirga maquilingensis gen. nov., sp. nov., a new genus of rod-shaped crenarchaeote isolated from a hot spring in the Philippines. Int I Syst Bacteriol 1999, 49 Pt 3:1157-1163.

74. Volkl P, Huber R, Drobner E, Rachel R, Burggraf S, Trincone A, Stetter KO: Pyrobaculum aerophilum sp. nov., a novel nitrate-reducing hyperthermophilic archaeum. Appl Environ Microbiol 1993, 59(9):2918-2926.

75. Huber R, Sacher M, Vollmann A, Huber H, Rose D: Respiration of arsenate and selenate by hyperthermophilic archaea. Syst Appl Microbiol 2000, 23(3):305-314.

76. Amo T, Paje ML, Inagaki A, Ezaki S, Atomi H, Imanaka T: Pyrobaculum calidifontis sp. nov., a novel hyperthermophilic archaeon that grows in atmospheric air. Archaea 2002, 1(2):113-121.

77. Huber R, Kristjansson JK, Stetter KO: Pyrobaculum gen. nov., a new genus of neutrophilic, rod-shaped archaebacteria from continental solfataras growing optimally at 100oC. Arch Microbiol 1987, 149(95-101)

78. The Prokaryotes: A handbook on the Biology of Bacteria. SpringerDworkin M, Falkow S, Rosenberg E, Schleifer K-H, Stackenbrandt E, 3rd 2006.

79. Stetter KO, Lauerer G, Thomm M, Neuner A: Isolation of Extremely Thermophilic Sulfate Reducers: Evidence for a Novel Branch of Archaebacteria. Science 1987, 236(4803):822-824.

80. Beeder J, Nilsen RK, Rosnes JT, Torsvik T, Lien T: Archaeoglobus fulgidus Isolated from Hot North Sea Oil Field Waters. Appl Environ Microbiol 1994, 60(4):1227-1231

81. Falb M, Pfeiffer F, Palm P, Rodewald K, Hickmann V, Tittor J, Oesterhelt D: Living with two extremes: conclusions from the genome sequence of Natronomonas pharaonis. Genome Res 2005, 15(10):1336-1343.

82. Oren A, Ginzburg M, Ginzburg BZ, Hochstein LI, Volcani BE: Haloarcula marismortui (Volcani) sp. nov., nom. rev., an extremely halophilic bacterium from the Dead Sea. Int J Syst Bacteriol 1990, 40(2):209-210.

83. Wende A, Furtwangler K, Oesterhelt D: Phosphate-dependent behavior of the archaeon Halobacterium salinarum strain R1. J Bacteriol 2009, 191(12):3852-3860

84. Bolhuis H, Palm P, Wende A, Falb M, Rampp M, Rodriguez-Valera F, Pfeiffer F, Oesterhelt D: The genome of the square archaeon Haloquadratum walsbyi : life at the limits of water activity. BMC Genomics 2006, 7:169

85. Robinson JL, Pyzyna B, Atrasz RG, Henderson CA, Morrill KL, Burd AM, Desoucy E, Fogleman RE 3rd, Naylor JB, Steele SM, et al: Growth kinetics of extremely halophilic archaea (family halobacteriaceae) as revealed by arrhenius plots. J Bacteriol 2005, 187(3):923-929.

86. Jones WJ, Leigh JA, Mayer F, Woese CR, Wolfe RS: Methanococcus jannaschii sp. nov., an extremely thermophilic methanogen from a submarine hydrothermal vent. Archives of Microbiology 1983, 136(4):254-261.

87. Jack Jones W, Paynter MJB, Gupta R: Characterization of Methanococcus maripaludis sp. nov., a new methanogen isolated from salt marsh sediment. Archives of Microbiology 1983, 135(2):91-97.
88. Kendall MM, Liu Y, Sieprawska-Lupa M, Stetter KO, Whitman WB, Boone DR: Methanococcus aeolicus sp. nov., a mesophilic, methanogenic archaeon from shallow and deep marine sediments. Int I Syst Evol Microbiol 2006, 56(Pt 7):1525-1529.

89. Jones JB, Stadtman TC: Methanococcus vannielii: culture and effects of selenium and tungsten on growth. J Bacteriol 1977, 130(3):1404-1406.

90. Sowers KR, Baron SF, Ferry JG: Methanosarcina acetivorans sp. nov., an Acetotrophic Methane-Producing Bacterium Isolated from Marine Sediments. Appl Environ Microbiol 1984, 47(5):971-978.

91. Maestrojuan GM, Boone DR: Characterization of Methanosarcina barkeri MST and 227, Methanosarcina mazei S-6T, and Methanosarcina vacuolata Z-76IT. Int J System Bacterio/ 1991, 41(2):267-274.

92. Franzmann PD, Springer N, Ludwig W, Conway de Macario E, Rohde M: A methanogenic archaeon from Ace Lake, Antarctica: Methanococcoides burtonii sp.nov. Syst Appl Microbiol 1992, 15:573-581.

93. Anderson IJ, Sieprawska-Lupa M, Goltsman E, Lapidus A, Copeland A, Glavina Del Rio T, Tice H, Dalin E, Barry K, Pitluck S, et al: Complete genome sequence of Methanocorpusculum labreanum type strain $\mathrm{Z}$. Standards in Genomic Sciences 2009, 1:197-203.

94. Liu Y, Boone DR, Sleat R, Mah RA: Methanosarcina mazei LYC, a New Methanogenic Isolate Which Produces a Disaggregating Enzyme. Appl Environ Microbiol 1985, 49(3):608-613.

95. Anderson IJ, Sieprawska-Lupa M, Lapidus A, Nolan M, Copeland A, Glavina Del Rio T, Tice H, Dalin E, Barry K, Saunders E, et al: Complete genome sequence of Methanoculleus marisnigri Romesser et al. 1981 type strain JR1. Standards in Genomic Sciences 2009, 1:189-196.

96. Kamagata $Y$, Mikami E: Isolation and characterization of a novel thermophilic Methanosaeta strain. Int I Syst Bacteriol 1991, 41:191-196.

97. Miller TL, Wolin MJ: Methanosphaera stadtmaniae gen. nov., sp. nov.: a species that forms methane by reducing methanol with hydrogen. Arch Microbiol 1985, 141(2):116-122.

98. Zeikus JG, Wolfe RS: Methanobacterium thermoautotrophicus sp. n., an anaerobic, autotrophic, extreme thermophile. J Bacterio/ 1972, 109(2):707-715.

99. Brauer SL, Cadillo-Quiroz H, Yashiro E, Yavitt JB, Zinder SH: Isolation of a novel acidiphilic methanogen from an acidic peat bog. Nature 2006, 442(7099):192-194

100. Miller TL, Wolin MJ, de Macario EC, Macario AJ: Isolation of Methanobrevibacter smithii from human feces. Appl Environ Microbiol 1982, 43(1):227-232.

101. Kurr M, Huber R, Konig H, Jannasch HW, Fricke H, Trincone A, Kristjansson JK, Stetter KO: Methanopyrus kandleri, gen. and sp. nov. represents a novel group of hyperthermophilic methanogens, growing at $110^{\circ} \mathrm{C}$. Arch Microbiol 1991, 156:239-247.

102. Schleper C, Puhler G, Kuhlmorgen B, Zillig W: Life at extremely low pH. Nature 1995, 375(6534):741-742.

103. Darland G, Brock TD, Samsonoff W, Conti SF: A thermophilic, acidophilic mycoplasma isolated from a coal refuse pile. Science 1970, 170(965):1416-1418

104. Kawashima T, Amano N, Koike H, Makino S, Higuchi S, Kawashima-Ohya Y, Watanabe K, Yamazaki M, Kanehori K, Kawamoto T, et al: Archaeal adaptation to higher temperatures revealed by genomic sequence of Thermoplasma volcanium. Proc Natl Acad Sci U S A 2000, 97(26):14257-14262.

105. Erauso G, Reysenbach AL, Godfroy A, Meunier J-R, Crump B, Partensky F, Baross JA, Marteinsson V, Barbier G, Pace NR, et al: Pyrococcus abyssi sp. nov., a new hyperthermophilic archaeon isolated from a deep-sea hydrothermal vent. Arch Microbiol 1993, 160:338-349.

106. Fiala G, Stetter KO: Pyrococcus furiosus sp. nov. represents a novel genus of marine heterotrophic archaebacteria growing optimally at $100^{\circ} \mathrm{C}$. Archives of Microbiology 1986, 145(1):56-61.

107. Gonzalez JM, Masuchi Y, Robb FT, Ammerman JW, Maeder DL, Yanagibayashi M, Tamaoka J, Kato C: Pyrococcus horikoshii sp. nov., a hyperthermophilic archaeon isolated from a hydrothermal vent at the Okinawa Trough. Extremophiles 1998, 2(2):123-130.

108. Morikawa M, Izawa Y, Rashid N, Hoaki T, Imanaka T: Purification and characterization of a thermostable thiol protease from a newly isolated hyperthermophilic Pyrococcus sp. Appl Environ Microbiol 1994, 60(12):4559-4566.

109. Sakai S, Imachi H, Hanada S, Ohashi A, Harada H, Kamagata Y: Methanocella paludicola gen. nov., sp. nov., a methane-producing 
archaeon, the first isolate of the lineage 'Rice Cluster I', and proposal of the new archaeal order Methanocellales ord. nov. Int I Syst Evol Microbiol 2008, 58(Pt 4):929-936.

110. [http://www.mbio.ncsu.edu/MB451/lecture/Archaea/lecture.html].

111. Konneke M, Bernhard AE, de la Torre JR, Walker CB, Waterbury JB, Stahl DA: Isolation of an autotrophic ammonia-oxidizing marine archaeon. Nature 2005, 437(7058):543-546

doi:10.1186/1752-0509-4-S1-S1

Cite this article as: Xue et al:: Archaic chaos: intrinsically disordered proteins in Archaea. BMC Systems Biology 2010 4(Suppl 1):S1.

Submit your next manuscript to BioMed Central and take full advantage of:

- Convenient online submission

- Thorough peer review

- No space constraints or color figure charges

- Immediate publication on acceptance

- Inclusion in PubMed, CAS, Scopus and Google Scholar

- Research which is freely available for redistribution

Submit your manuscript at www.biomedcentral.com/submit
C Biomed Central 